Atmos. Meas. Tech. Discuss., doi:10.5194/amt-2015-337, 2016

Manuscript under review for journal Atmos. Meas. Tech.

Published: 2 February 2016

(c) Author(s) 2016. CC-BY 3.0 License.

(c) (i)

\title{
Experimental assessment of the lidar polarizing sensitivity
}

\author{
L. Belegante ${ }^{1}$, J. A. Bravo-Aranda ${ }^{2,3}$, V. Freudenthaler ${ }^{4}$, D. Nicolae ${ }^{1}$, A. Nemuc ${ }^{1}$, L. \\ Alados-Arboledas ${ }^{2,3}$, A. Amodeo ${ }^{5}$, G. Pappalardo ${ }^{5}$, G. D’ Amico ${ }^{5}$, R. Engelmann ${ }^{6}$, H. Baars ${ }^{6}$, U. \\ Wandinger $^{6}$, A. Papayannis ${ }^{7}$, P. Kokkalis ${ }^{7}$, and S. N. Pereira ${ }^{8}$ \\ ${ }^{1}$ National Institute of Research and Development for Optoelectronics, 409 Atomistilor Str, Magurele, Romania \\ ${ }^{2}$ Andalusian Institute for Earth System Research, Granada, Spain \\ ${ }^{3}$ Department of Applied Physcis, Unversity of Granada, Granada, Spain \\ ${ }^{4}$ Meteorological Institute, Ludwig-Maximilians-Universitat, Theresienstr. 37, 80333 Munich, Germany \\ ${ }^{5}$ Istituto di Metodologie per l'Analisi Ambientale CNR-IMAA, C.da S. Loja, Tito Scalo, Potenza 85050, Italy \\ ${ }^{6}$ Leibniz Institute for Tropospheric Research, Permoserstr. 15, 04318 Leipzig, Germany \\ ${ }^{7}$ National Technical University of Athens (NTUA), Physics Department, Heroon Polytechniou 9, 15780 Zografou, Athens, \\ Greece \\ ${ }^{8}$ Evora Geophysics Center, Rua Romao Ramalho 59, 7000, Evora, Portugal \\ Correspondence to: J. A. Bravo-Aranda (jabravo@ugr.es)
}

\begin{abstract}
Particle depolarization ratio retrieved from lidar measurements are commonly used for aerosol typing studies, microphysical inversion, or mass concentration retrievals. The particle depolarization ratio is one of the primary parameters that can differentiate several major aerosol components, but only if the measurements are accurate enough. The uncertainties related to the retrieval of particle depolarization ratios are the main factor in determining the accuracy of the derived parameters in

5 such studies. This paper presents an extended analysis of different depolarization calibration procedures, in order to reduce the related uncertainties. The calibration procedures are specific to each lidar system of the European Aerosol Research Lidar Network - EARLINET with polarising capabilities. The results illustrate a significant improvement of the depolarization lidar products for all the selected lidar stations. The calibrated volume and particle depolarization profiles at $532 \mathrm{~nm}$ show values that agree with the theory for all selected atmospheric constituents (several aerosol species, ice particles and molecules in the aerosol free regions).
\end{abstract}

\section{Introduction}

Uncertainties related to the influence of anthropogenic activities on the Earth's energy budget and climate change have lead to a real interest regarding the aerosols direct and indirect radiative effects. Measurements of vertically resolved aerosol optical properties (as the one performed by lidar systems) try to reduce these uncertainties. These systems are laser-based instruments able to provide quantitative information on aerosol layering and their properties (Measures et al., 1992). The principle is based on the detection of backscattered light that results from the interaction of the emitted laser light with the atmospheric constituents. Fig.1 shows the main components of a lidar system with polarising capabilities.. The emitted laser light is oriented towards the atmosphere by means of the emission optics. After the emitted light interacted with atmospheric constituents, the backscattered light is collected by a telescope and directed to the wavelength separation unit (WSU- named also the receiving 
Atmos. Meas. Tech. Discuss., doi:10.5194/amt-2015-337, 2016

Manuscript under review for journal Atmos. Meas. Tech.

Published: 2 February 2016

(c) Author(s) 2016. CC-BY 3.0 License.
Atmospheric

Measurement

Techniques

Discussions

optics unit for this study), Polarizing Beam Splitter (PBS) and photomultipliers (PMTs). The receiving optics (mirrors, lenses and dichroic filters), the PBS, and the PMTs will be treated as distinct units, since the effects of each unit alters the depolarization profiles from different perspectives. The collected laser light contains information about to the optical properties of the atmospheric components, and consequently to their size, shape and composition. Methods to retrieve these properties from elastic backscatter, Raman, multi-wavelength and depolarization lidars are already described in details in the literature (Fernald et al., 1972; Klett et al., 1981, 1985; Kovalev and Eichinger, 2004). According to their application, lidar systems have different configurations, channel combinations and geometries. For atmospheric studies, the configuration of a lidar system narrows down to several types and optical layouts. A major breakthrough in atmospheric studies is the development of global lidar networks, able to provide systematic lidar dataflow with a large temporal and spatial coverage (Earlinet , 2014a). The European Aerosol Research Lidar Network - EARLINET data (Pappalardo et al., 2012, 2014) is relevant for climatology, regional and large scale models but also for special events such as Saharan dust outbreaks, transport of smoke plumes or volcanic ash over Europe (Earlinet , 2014b, d, e), (Papayannis et al., 2008; Ansmann et al., 2009; Ansmann and Bosenberg, 2003; Nicolae et al., 2013; Mona et al., 2012). The multi-wavelength depolarization Raman lidar systems used in EARLINET $(3 \beta+2 \alpha+\delta$ lidar systems - Mona et al., 2012), are capable to provide an extended set of optical parameters for aerosol characterization, by assuring the quality of the products through internal data quality procedures. For depolarization studies, most of the lidar systems are designed to measure with two channels (parallel and cross). Recent atmospheric studies using remote sensing data have been dedicated to aerosol typing, microphysical inversion and aerosol mass concentration retrievals. Since all relevant parameters are shape dependent (Hervo et al., 2012; Hogan et al., 2012; Gross et al., 2015), the depolarization products obtained from lidar measurements proved to be essential, giving the opportunity to distinguish between rather spherical particles with low depolarization ratios, and non-spherical particles with higher depolarization ratios (Gasteiger et al., 2014). Still, most questions are related to the accuracy of the lidar products used for these studies (lidar ratio, particle linear depolarization ratio, Ångström exponent). Lidar measurements of particle linear depolarization ratio are often used to discriminate between low depolarizing (e. g. local aerosol) and high depolarizing (dust) aerosols, or liquid and ice clouds, requiring only a relative measure of these parameters. At the present state, the uncertainties of these products are high and any aerosol classification based on relative lidar depolarization profiles is challenging. For aerosol typing and mass concentration studies, absolute values of particle linear depolarization ratio are needed. According to (Petzold et al., 2010; Gross et al., 2013; Burton et al., 2012), the particle linear depolarization values characterizing several aerosol species (or mixtures of aerosols) ranges around similar values: for aged dust, the particle depolarization value at $532 \mathrm{~nm}$ ranges from 0.21 to 0.29 and for pure dust from 0.30 to 0.39 with a lidar ratio (LR) overlapping from 40 to $60 \mathrm{sr}$ for aged dust and 35 to $63 \mathrm{sr}$ for pure dust respectively. The same issue emerges when discriminating between biomass burning aerosol mixed with mineral dust and industrial pollution aerosol, with values around 0.1 to 0.2 (LR 36-90 sr) for the first and 0.04 to 0.1 (LR 35-70 sr) for the second. Therefore, in order to discriminate between different type of particles, the uncertainty of these products has to be significantly improved, e.g. by reducing and / or correcting for instrumental errors. Currently, most lidar depolarization studies are performed assuming ideal lidar optics with no influence on the final depolarization products ( volume and particle linear depolarization ratio). Recent studies showed that even small deviations from the ideal assumptions can lead to large uncertainties of the retrieved depolarization products. 
Atmos. Meas. Tech. Discuss., doi:10.5194/amt-2015-337, 2016

Manuscript under review for journal Atmos. Meas. Tech.

Published: 2 February 2016

(c) Author(s) 2016. CC-BY 3.0 License.

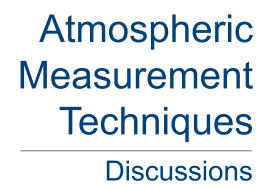

(c) (i)

Typically, the main source of uncertainty does not come from the detected signal (noise), but from systematic errors in the optical setup of the lidar systems (Freudenthaler et al., 2009; Freudenthaler, 2015; Alvarez et al., 2006; Snels et al., 2009; Biele et al., 2000). One of the most efficient method in measuring the absolute value of depolarization parameters is by implementing hardware depolarization calibration methods. This study aims to present several techniques developed to calibrate the lidar depolarization channels. Moreover, methods for assessing the influence of lidar optics on depolarization products (i.e., the assessment of the receiving optics diattenuation parameter and the rotation of the plane of polarization of the laser around the light propagation axis with respect to the PBS) in order to reduce the corresponding uncertainties (Mattis et al., 2009) are discussed. The paper presents an extended analysis of different depolarization calibration procedures specific to each lidar setup (or cluster of similar systems) in EARLINET. The analysis is focused on the two channels setup, designed to measure the backscattered signal components polarised parallel and perpendicular (cross) with respect to the linear polarization of the emitted light, but can be further developed to be applied for many optical layouts. The first part of the paper describes the theoretical background, architecture and methodology used for depolarization calibration procedures, including a broad description of the available calibration procedures, but also new techniques for performing the calibration of lidar depolarization channels. New methods to retrieve the influence of different optical modules on depolarization products are also presented and discussed. Methods to assess and correct the rotation of the plane of polarization of the laser around the light propagation axis $(\alpha)$ are also introduced and discussed. Section 2 describes the theoretical background based on the Mueller-Stokes formalism used as the basis for the entire study. The methodology is given in section 3. The second part of the paper shows results of calibrated and not-calibrated lidar depolarization profiles, several case studies from different lidar instruments in EARLINET, discussions and conclusions. Volume and particle linear depolarization ratios are presented, emphasizing the added value of calibrated depolarization channels, especially when quantitative information is envisaged. The results show the impact of the studies (calibration of the depolarization channels and influence of the optics) on primary lidar products and implicitly on aerosol typing results. Section 4 shows the results and discussions and the conclusions are given in section 5 . The experimental approach of the paper is designed to present how depolarization calibration procedures are implemented. Most of the available literature is focused on the theoretical perspective of the topic and practical issues usually remain an open topic. A hands on approach for the assessment of the lidar polarization sensitivity is most welcomed since most of these calibration techniques require comprehensive practical descriptions that must be treated thoroughly.

\section{Theoretical background}

The Mueller-Stokes formalism (Chipman, 2009; Ossikovski et al., 2010; Lu and Chipman, 1996) describing the lidar system setup (shown in Fig.1) can be summarized by the following equation (Freudenthaler, 2015):

$$
\begin{aligned}
I_{S}= & \eta_{S} \mathbf{M}_{S} \mathbf{R}(y) \mathbf{M}_{0}\left(\gamma, D_{0}\right) \\
& \cdot \mathbf{F}(a) \mathbf{M}_{E}(\beta) I_{L}\left(\alpha, a_{L}\right)
\end{aligned}
$$


Atmos. Meas. Tech. Discuss., doi:10.5194/amt-2015-337, 2016

Manuscript under review for journal Atmos. Meas. Tech.

Published: 2 February 2016

(c) Author(s) 2016. CC-BY 3.0 License.

(c) (i)

$\begin{array}{r}\text { Atmospheric } \\ \text { Measurement } \\ \text { Techniques } \\ \hline \text { Discussions }\end{array}$

where bold italic fonts are used for the Stokes vectors, bold for the Mueller matrices and italic for the scalar variables. $\boldsymbol{I}_{L}\left(\alpha, \mathrm{a}_{L}\right)$ is the Stokes vector of the light emitted by the laser, $\mathbf{M}_{E}$ is the Mueller matrix of the emission block optics, $\mathbf{F}$ represents the Mueller matrix of the atmospheric scattering volume in backscattering direction, $a$ is the polarization parameter of the atmospheric volume described below in more detail, $\mathbf{M}_{0}$ is the receiving optics matrix characterized by the receiving optics diattenuation parameter $D_{0}, \mathbf{R}(\mathrm{y})$ is the rotation matrix, $y$ describes the optical setup type (see Fig 2.a-b). $\mathbf{M}_{S}$ stands for both parts of the polarizing beam splitter, i.e. the transmitted (subscript $\mathrm{T}$ ) and reflected (subscript $\mathrm{R}$ ) channels, including additional polarizing elements after the polarizing splitter. The incident plane of the polarizing beam splitter is taken as the reference plane for all rotation angles around the optical axis. $\eta$ represents the calibration factor including only the electronic amplification and the optical diattenuation of the two polarizing channels and $\boldsymbol{I}_{S}$ is the Stokes vector for the two detected channels (i.e. $\boldsymbol{I}_{R}$ and $\boldsymbol{I}_{T}$ ) (see also Fig 1) where the Stokes vector describes the polarisation state of the measured channels (either transmitted or reflected). $\alpha$ is the rotation of the plane of polarization of the laser around the propagation axis, $a_{L}$ is the polarization parameter of the light beam leaving the laser, $\beta$ is the rotation of the emitter optics around the propagation axis, $\gamma$ is the rotation of the receiver optics around the propagation axis. In order to have a complete characterization of the lidar optics, the contribution of all latter parameters must be accounted. The technological solutions for mounting the receiving optics and the PBS are based on high precision optical mounts for all the considered lidar setups. These implementations assure high accuracy and minimization of any rotation misalignment of the optics. The analyzed EARLINET lidars have the $\gamma$ and $\beta$ angles lower than $0.5^{\circ}$ as indicated by (Bravo-Aranda et al., 2015). Since the larger uncertainties are expected for $D_{O}$ and $\alpha$, we neglect the effect of $\gamma$ and $\beta$ angles on these lidar systems.

A significant simplification comes from the "v" component of the emitted Stokes vector (i,q,u,v) (Chipman, 2009), (Lu and Chipman, 1996), (Freudenthaler, 2015), (Ossikovski et al., 2010). By neglecting this component, we assume that the emitting optics does not have retardation effects. This simplification can be performed once the $\alpha$ parameter is corrected and the $\beta$ and $\gamma$ angles are negligible.

The polarizing beam splitter cross talk can also be neglected since all lidar systems described in this study are equipped with additional polarization filters placed after the PBS on both transmitted and reflected channels, aiming to minimize this effect in an efficient way. The polarization parameter of the light beam leaving the laser $a_{L}$ will be neglected since for this study, the polarization of the emitted light will be considered 1. This does not apply for all lidar systems, but for simplification reasons we will consider instruments equipped with ideal light sources. In this study we consider only the gain ratio $\eta^{*}$, the rotation of the plane of polarization of the laser around the propagation axis $\alpha$ and the diattenuation parameter of the receiver optics $\mathrm{D}_{0}$. Freudenthaler (2015) describes in details, all the terms and the variables present in Eq. (1). According to that, the Mueller 
Atmos. Meas. Tech. Discuss., doi:10.5194/amt-2015-337, 2016

Manuscript under review for journal Atmos. Meas. Tech.

Published: 2 February 2016

(c) Author(s) 2016. CC-BY 3.0 License.

\section{(c) (i)}

matrix describing the atmospheric backscatter is:

$$
\begin{gathered}
\mathbf{F}=\left(\begin{array}{cccc}
F_{11} & 0 & 0 & 0 \\
0 & F_{22} & 0 & 0 \\
0 & 0 & -F_{22} & 0 \\
0 & 0 & 0 & F_{44}
\end{array}\right)= \\
F_{11}\left(\begin{array}{cccc}
1 & 0 & 0 & 0 \\
0 & a & 0 & 0 \\
0 & 0 & -a & 0 \\
0 & 0 & 0 & 1-2 a
\end{array}\right)
\end{gathered}
$$

$5 a=\frac{F_{22}}{F_{11}}$

Consequently, the linear depolarisation ratio of the atmospheric scattering volume $(\delta)$ can be defined as

$\delta=\frac{F_{11}-F_{22}}{F_{11}+F_{22}}=\frac{1-a}{1+a} \Rightarrow a=\frac{1-\delta}{1+\delta}$

All optical elements $\mathbf{M}_{O}$ can be described by Mueller matrices of diattenuators $\mathbf{M}_{D}$ with retardation $\mathbf{M}_{r e t}$ :

$$
\begin{aligned}
& \mathbf{M}_{O}=\mathbf{M}_{D} \mathbf{M}_{r e t}=T_{O}\left(\begin{array}{cccc}
1 & D_{O} & 0 & 0 \\
D_{O} & 1 & 0 & 0 \\
0 & 0 & Z_{O} & 0 \\
0 & 0 & 0 & Z_{O}
\end{array}\right) . \\
& \left(\begin{array}{cccc}
1 & 0 & 0 & 0 \\
0 & 1 & 0 & 0 \\
0 & 0 & \mathrm{c}_{O} & \mathrm{~s}_{O} \\
0 & 0 & -\mathrm{s}_{O} & \mathrm{c}_{O}
\end{array}\right)= \\
& =T_{O}\left(\begin{array}{cccc}
1 & D_{O} & 0 & 0 \\
D_{O} & 1 & 0 & 0 \\
0 & 0 & Z_{O} c_{O} & Z_{O \mathrm{~s}_{O}} \\
0 & 0 & -Z_{O \mathrm{~s}_{O}} & Z_{O} \mathrm{c}_{O}
\end{array}\right)
\end{aligned}
$$

10

with

$$
\begin{aligned}
& T_{O}=\frac{T_{O}^{p}+T_{O}^{s}}{2}, D_{O}=\frac{T_{O}^{p}-T_{O}^{s}}{T_{O}^{p}+T_{O}^{s}}, Z_{O}=\frac{2 \sqrt{T_{O}^{p} T_{O}^{s}}}{T_{O}^{p}+T_{O}^{s}}=\sqrt{1-D_{O}^{2}}, \\
& \mathrm{c}_{O}=\cos \Delta_{O}, \mathrm{~s}_{O}=\sin \Delta_{O}, \Delta_{O}=\varphi_{O}^{p}-\varphi_{O}^{s}
\end{aligned}
$$

where $\Delta_{O}$ is the differential phase shift of the $\mathrm{p}$ and s light components and $T_{O}^{p}, T_{O}^{s}$ are the optics intensity transmission for parallel (p) and cross (s) linearly polarised light with respect to the plane of incidence of the PBS. We don't investigate the effects of the emitter optics described by the Mueller matrix $\mathbf{M}_{E}$ in this study, since at least two of the considered lidars send 
Atmos. Meas. Tech. Discuss., doi:10.5194/amt-2015-337, 2016

Manuscript under review for journal Atmos. Meas. Tech.

Published: 2 February 2016

(c) Author(s) 2016. CC-BY 3.0 License.

(c) (i)
Atmospheric

Measurement

Techniques

Discussions

the laser radiation in the atmosphere without using any optic (MUSA and MULIS). For lidar systems that use emission optics to send the laser radiation in the atmosphere, further investigations are needed to fully characterize the effects of $\mathbf{M}_{E}$ on the depolarization products (Bravo-Aranda et al., 2015). We also assume that the light emitted to the atmosphere, $\boldsymbol{I}_{E}$, is linearly polarised with an angle $\alpha$ with respect to the reference plane, which reduces Eq. (1) to

$5 \quad \boldsymbol{I}_{S}=\eta_{S} \mathbf{M}_{S} \mathbf{R}(\mathrm{y}) \mathbf{M}_{O}\left(\gamma, D_{O}\right) \mathbf{F}(a) \boldsymbol{I}_{L}(\alpha)$

The calibrated signal ratio including cross talk and alignment errors $\delta^{*}$ can be calculated from the measured signals using the calibration factor $\eta$ :

$\delta^{*}=\frac{1}{\eta} \cdot \frac{I_{R}}{I_{T}}$

In order to determine the calibration factor $\eta$, we use the calibration methods described further on in the paper. The general

formula for the retrieved light intensity is described in (Freudenthaler, 2015), Sect. 4. The detected light intensity for the p and c components can be described by

$$
\begin{array}{r}
\frac{I_{S}(\mathrm{y}, \varepsilon, \gamma, a, \beta, \alpha)}{\eta_{S} T_{S} T_{O} F_{11} T_{E} I_{L}}= \\
\left(1+\mathrm{y} D_{S} D_{O} \mathrm{c}_{2 \gamma+2 \varepsilon}\right) i_{E}-\mathrm{y} D_{S} Z_{O} \mathrm{~s}_{O} \mathrm{~s}_{2 \gamma+2 \varepsilon} v_{E}+ \\
+a D_{O}\left(\mathrm{c}_{2 \gamma} q_{E}-\mathrm{s}_{2 \gamma} u_{E}\right)+ \\
+a y D_{S}\left(c_{2 \varepsilon} q_{E}+s_{2 \varepsilon} u_{E}\right)- \\
-a y D_{S} s_{2 \gamma+2 \varepsilon}\left(W_{O}\left(s_{2 \gamma} q_{E}+c_{2 \gamma} u_{E}\right)-2 Z_{O} s_{O} v_{E}\right)
\end{array}
$$$$
15
$$

For the total signal (Fig 2.c), the detected light intensity can be described by

$$
\begin{array}{r}
\frac{I_{t o t}(\mathrm{y}, \varepsilon, \gamma, a, \beta, \alpha)}{\eta_{t} T_{t} T_{O} F_{11} T_{E} I_{L}}= \\
i_{E}+\mathrm{a} D_{O}\left(\mathrm{c}_{2 \gamma} q_{E}-\mathrm{s}_{2 \gamma} u_{E}\right)
\end{array}
$$

where $c_{\ldots}=\cos (\ldots), s_{\ldots}=\sin (\ldots), \varepsilon$ is the error angle of the $\Delta 90^{\circ}$ calibration setup and $i, q, u$, $v$ are the Stokes components of the emitted light.

$$
W_{O}=1-Z_{O} c_{O}, \quad D_{S}=\frac{T_{S}^{p}-T_{S}^{s}}{T_{S}^{p}+T_{S}^{s}}
$$

For horizontal or vertical linear polarised laser and without rotational misalignment of the emission optics, receiver optics, laser and of the calibrator, i.e.

$u_{E}=v_{E}=0, i_{E}=q_{E}=+1 \wedge \gamma=\varepsilon=0 \wedge a_{L}=1$

we have

$\frac{I_{S}(\mathrm{y}, 0,0, a, 0,0)}{\eta_{S} T_{S} T_{O} F_{11} T_{E} I_{L}}=\left(1+\mathrm{y} D_{S} D_{O}\right)+a\left\{D_{O}+\mathrm{y} D_{S}\right\}$ 
Atmos. Meas. Tech. Discuss., doi:10.5194/amt-2015-337, 2016

Manuscript under review for journal Atmos. Meas. Tech.

Published: 2 February 2016

(c) Author(s) 2016. CC-BY 3.0 License.

\section{(c) (P)}

and with a cleaned polarising beam splitter (additional polarization filters placed after the PBS to minimize the cross talk)

$D_{R}=-1, D_{T}=+1 \Rightarrow D_{S}= \pm 1$

resulting

5

$$
\begin{array}{r}
\frac{I_{S}(\mathrm{y}, 0,0, a, 0,0)}{\eta_{S} T_{S} T_{O} F_{11} T_{E} I_{L}}= \\
=\left(1 \pm \mathrm{y} D_{O}\right)+a\left(D_{O} \pm \mathrm{y}\right)= \\
=\left(1 \pm \mathrm{y} D_{O}\right)+\mathrm{y} a\left(\mathrm{y} D_{O} \pm 1\right)= \\
=\left(1 \pm \mathrm{y} D_{O}\right) \pm \mathrm{y} a\left(1 \pm \mathrm{y} D_{O}\right)= \\
=\left(1 \pm \mathrm{y} D_{O}\right)(1 \pm \mathrm{y} a)
\end{array}
$$

10 we then have

$$
\frac{I_{R}}{I_{T}}=\frac{\eta_{R} T_{R}}{\eta_{T} T_{T}} \frac{\left(1-\mathrm{y} D_{O}\right)(1-\mathrm{y} a)}{\left(1+\mathrm{y} D_{O}\right)(1+\mathrm{y} a)}
$$

where $\eta_{R}$ and $\eta_{T}$ are the electronic amplification of individual transmitted/reflected channels. $\mathrm{T}_{R}$ and $\mathrm{T}_{T}$ are the transmission and reflectance for un-polarised light passing through the PBS.

With Eqs. (4) and (16)

$15 \mathrm{y}=+1 \Rightarrow \delta=\frac{1}{\eta} \frac{I_{R}}{I_{T}} \frac{1+D_{O}}{1-D_{O}}=\frac{1}{\eta^{*}} \frac{I_{R}}{I_{T}}$

for

$\mathrm{y}=-1 \Rightarrow \delta=\eta \frac{I_{T}}{I_{R}} \frac{1+D_{O}}{1-D_{O}}=\eta^{*} \frac{I_{T}}{I_{R}}$

with

$$
\eta=\frac{\eta_{R} T_{R}}{\eta_{T} T_{T}}
$$

20 the calibration factor that only takes into account detection efficiencies and optics transmission after the PBS. For more general or other special cases see (Freudenthaler, 2015).

\section{Methodology}

\subsection{Determination of the gain ratio $\eta^{*}$ : calibration procedures}

The calibration of depolarization channels is specific to each lidar system, but the basic principles are similar for most of the instruments. The calibration of the depolarization channels consists of assessing the gain ratio $\eta^{*}$. This parameter includes the calibration factor but can also include the cross talk from optics before the polarising beam splitter and system alignment errors. 
Atmos. Meas. Tech. Discuss., doi:10.5194/amt-2015-337, 2016

Manuscript under review for journal Atmos. Meas. Tech.

Published: 2 February 2016

(c) Author(s) 2016. CC-BY 3.0 License.

(c) (i)

Atmospheric

Measurement

Techniques

Discussions

In order to determine the gain ratio $\eta^{*}$, the first solution is to use the " $0^{\circ}$ calibration" or the "atmospheric calibration". Using this calibration, the contribution of the system to the final lidar depolarization products is assessed by using an aerosol-free range in the lidar signal (Freudenthaler et al., 2009), an altitude where only the molecular contribution has to be considered. In a such atmospheric region, the total volume linear depolarisation ratio can be approximated by the well known value of

5 the air molecule linear depolarisation ratio (Behrendt and Nakamura, 2002). Usually this calibration (normalization), applied to the depolarization profile does not take into account all the effects that have to be corrected in the depolarization profile (i.e., crosstalk coefficient, diattenuation effects, phase shift, etc.), resulting in erroneous depolarization values especially in highly depolarizing aerosol layers. Another critical drawback of this calibration method is the presence of even small amounts of highly depolarizing aerosol (e.g. ice crystals) in the assumed clean range which can easily lead to large errors in the final depolarization products (Freudenthaler et al., 2009; Freudenthaler, 2015).

A better and more reliable solution to calibrate the depolarisation measurements is represented by the " $45^{\circ}$ calibration". This calibration implies a $45^{\circ}$ rotation of the depolarization analyzer (PBS and the PMTs) with respect to the polarization plane of the laser, in order to equalize the light intensity in the cross and parallel channels. When comparing the calibration signals, the difference between the transmitted and reflected channels is given by the contribution of optics and electronics in the lidar receiving unit, e.g. diattenuation effects of optical components in the receiving unit, detection efficiencies of the PMTs, different optics in front of the detectors - like the presence of any neutral density filters, and different gains of the pre-amplifiers and amplifiers for each channel. The $45^{\circ}$ rotation between the input (laser) polarization plane and the polarising beam splitter axis can be technically implemented by physical (mechanical) rotation of the whole depolarization analyzer or by the rotation of an additional half wave plate (HWP) optic (Fig 3.b-c). A further solution can be the use of a polarising filter at $45^{\circ}$ with respect to the incident plane of the polarising beam splitter. The implementation of this methods will be further described in this study.

(Freudenthaler, 2015) describes these calibration techniques in a quite general context. In this study we consider only the rotation of the emitted laser polarisation and the diattenuation of the receiving optics. The gain ratio is determined using

$\eta^{*}(y, x)=\frac{I_{R}(y, x)}{I_{T}(y, x)}$

25 with $\mathrm{x}= \pm 1$

The main source of uncertainty involved in this kind of calibration is represented by the accuracy in determining the rotation of $45^{\circ}$. The less is this accuracy the large is the errors in estimating the calibration constant. A better solution is to use two subsequent measurements performed by rotating the depolarization analyzer at $\pm 45^{\circ}$ with respect to the default measuring position. This calibration is called the " $\pm 45^{\circ}$ calibration". The calibration constant is determined by using the geometric mean of the two $\pm 45^{\circ}$ measurements. The two measurements are designed to compensate each other even for cases where the $45^{\circ}$ rotation uncertainty is significant (Freudenthaler et al., 2009). A more general solution is to use two subsequent measurements performed by rotating the depolarization analyzer with an exact $90^{\circ}$ difference between each other. This calibration method is called the " $\Delta 90^{\circ}$ calibration" and the output is similar with the one from the $\pm 45^{\circ}$ calibration. The " $\pm 45^{\circ}$ calibration" can 
Atmos. Meas. Tech. Discuss., doi:10.5194/amt-2015-337, 2016

Manuscript under review for journal Atmos. Meas. Tech.

Published: 2 February 2016

(C) Author(s) 2016. CC-BY 3.0 License.
Atmospheric

Measurement

Techniques

Discussions

be considered a particular case of the " $\Delta 90^{\circ}$ rotation calibration" since the only constrain of this calibration is the $90^{\circ}$ angle between the two measurements.

Technically, the " $\Delta 90^{\circ}$ calibration" can be implemented by using a mechanical rotator (holder), which rotates the optical components at fixed $\Delta 90^{\circ}$ angles. This calibrator will be further called the " $\Delta 90^{\circ}$ mechanical rotation calibrator". A similar approach (same output) can be considered if we use a HWP for accurately rotating the emitted or collected light at $\Delta 90^{\circ}$. The advantage is that while the mechanical rotator can only be placed in the reception unit (in front of the receiving optics or in front of the PBS), the HWP module can be also placed at the emission, in front and after the emission optics. This calibrator will be further called the " $\Delta 90^{\circ}$ HWP calibrator". A third approach of the " $\Delta 90^{\circ}$ calibration" is the use of an additional linear polarizer that can be rotated at fixed $\Delta 90^{\circ}$ angles. In this case, the $\Delta 90^{\circ}$ rotation will be replaced by the additional linear polarizer. According to its position in the optical chain (in front of the telescope or the PBS in the receiving unit) the calibration can account for all lidar optics placed after the polarizer (e.g. receiving optics, PBS, PMT). Further on, this calibrator will be called the " $\Delta 90^{\circ}$ polarizer rotation calibrator". In order to perform the latter calibration, the 'zero' position of the optical module (polariser or HWP) in respect to the relative position of the PBS must be determined and corrected for. For this, the $\Delta 90^{\circ}$ rotation calibration requires an extra measurement set to assess the offset angle between the calibrator and the zero position of the PBS.

For exemplification, the error angle of the calibration setup $(\varepsilon)$ must be estimated to allow a reliable measurement of the calibration constant using the $\Delta 90^{\circ}$ polarizer calibration. In order to determine $\varepsilon$, a set of two relative $\pm 45^{\circ}$ measurements is required. The polarizer is placed in a random position relative to the polarization plane of the receiving optics. Two measurements will be performed with the polarizer rotated precisely at $\pm 45^{\circ}$ from the $\varepsilon$ angle.

In cases when the $\pm 45^{\circ}$ calibration factor can be described by

$\frac{\eta^{*}(y, x, \varepsilon)}{\eta}=f(y, \ldots) \frac{1+K x s_{2 \varepsilon}}{1-K x s_{2 \varepsilon}}$

with $\mathrm{K} \leq(1-$ a) parameter taking into account instrument contributions except $\mathrm{x}$ and $\varepsilon$. It is possible to determine the calibration rotation $\varepsilon$ from

$$
\begin{array}{r}
Y(\varepsilon, K)=\frac{\eta_{p o l}^{*}\left(y,+45^{\circ}, \varepsilon, K\right)-\eta_{p o l}^{*}\left(y,-45^{\circ}, \varepsilon, K\right)}{\eta_{p o l}^{*}\left(y,+45^{\circ}, \varepsilon, K\right)+\eta_{p o l}^{*}\left(y,-45^{\circ}, \varepsilon, K\right)} \\
=\frac{2 K s_{2 \varepsilon}}{1+K^{2} s_{2 \varepsilon}^{2}}
\end{array}
$$

$\varepsilon=\frac{1}{2} \arcsin \left[\frac{1}{K} \tan \left(\frac{\arcsin (Y(\varepsilon, K))}{2}\right)\right]$

the formulas can be applied to:

- polarizer before the PBS:

$30 \frac{\eta^{*}(y, x, \varepsilon)}{\eta}=\frac{1+x y s_{2 \varepsilon}}{1-x y s_{2 \varepsilon}}$ 
Atmos. Meas. Tech. Discuss., doi:10.5194/amt-2015-337, 2016

Manuscript under review for journal Atmos. Meas. Tech.

Published: 2 February 2016

(c) Author(s) 2016. CC-BY 3.0 License.

\section{(c) (P)}

- polarizer before the receiving optics:

$\frac{\eta^{*}(y, x, \varepsilon)}{\eta}=\frac{1-y D_{O}}{1+y D_{O}} \frac{1+x y s_{2 \varepsilon}}{1-x y s_{2 \varepsilon}}$

- or the polarizer after the emitter optics:

$\frac{\eta^{*}(y, x, \varepsilon)}{\eta}=\frac{1-y D_{O}}{1+y D_{O}} \frac{1+\text { xyas }_{2 \varepsilon}}{1-\text { xyas }_{2 \varepsilon}}$

Assessment of the calibrator rotation angle can only be performed in stable atmospheric conditions. The altitude variation of $\mathrm{Y}$ is caused by the dependency of $\eta$ with atmospheric depolarization. The assessment of $\varepsilon$ will be performed only in aerosol free regions where the atmospheric depolarization is minimal. For a $\equiv \mathrm{K}<1$ we use a successive approximation method to find a first approximation $\varepsilon_{1}$ by setting $\mathrm{K}=1$ in the previous equation.

$$
\varepsilon_{1}=\frac{1}{2} \arcsin \left[\tan \left(\frac{\arcsin (Y(\varepsilon, K))}{2}\right)\right]<\varepsilon
$$

after adjusting the polarizer rotation calibrator according with $\varepsilon_{1}$, another assessment of $\varepsilon$ at $\left(\varepsilon-\varepsilon_{1}\right)$ must be performed. This results in

$$
Y\left(\varepsilon-\varepsilon_{1}, K\right)=\frac{2 K s_{2\left(\varepsilon-\varepsilon_{1}\right)}}{1+K^{2} s_{2\left(\varepsilon-\varepsilon_{1}\right)}^{2}}
$$

From Eqs. (22) and (28) we find a better approximation for $\varepsilon$ from the two measurements

$$
\begin{aligned}
\frac{Y\left(\varepsilon-\varepsilon_{1}, K\right)}{Y(\varepsilon, K)} & =\frac{\left(1+K^{2} s^{2}{ }_{2 \varepsilon}\right) 2 K s_{2\left(\varepsilon-\varepsilon_{1}\right)}}{\left(1+K^{2} s^{2}{ }_{2\left(\varepsilon-\varepsilon_{1}\right)}\right) 2 K s_{\varepsilon}} \approx \\
& \approx \frac{s_{2\left(\varepsilon-\varepsilon_{1}\right)}}{s_{2 \varepsilon}} \approx \frac{\left(\varepsilon-\varepsilon_{1}\right)}{\varepsilon}=1-\frac{\varepsilon_{1}}{\varepsilon}
\end{aligned}
$$

$\Rightarrow$

$\varepsilon_{2} \approx \frac{Y(\varepsilon, K)}{Y(\varepsilon, K)-Y\left(\varepsilon-\varepsilon_{1}, K\right)}$

Furthermore, by using Eq.(29) we can use the retrieved $\varepsilon_{2}$ to estimate K.

$$
K_{2}=\frac{1}{\sin \left(2 \varepsilon_{2}\right)} \tan \left(\frac{\arcsin [Y(\varepsilon, K)]}{2}\right)
$$

It can be shown that using the estimated $K_{2}$ with Eq.(23) to get $\varepsilon_{3}$ and then Eq.(30) to get $\varepsilon_{4}$ and Eq.(31) to get $K_{4}$, they rapidly approach the real $\varepsilon$ and $\mathrm{K}$. After assessment (and correction) of $\varepsilon$, the gain ratio can be calculated from the geometric mean of the $\pm 45^{\circ}$ measurements:

$$
\begin{aligned}
\eta_{\Delta 90}^{*}(y, x)= & \sqrt{\eta^{*}\left(y,-45^{\circ}\right) \eta^{*}\left(y,+45^{\circ}\right)}= \\
& =\sqrt{\frac{I_{R}\left(y,+45^{\circ}\right)}{I_{T}\left(y,+45^{\circ}\right)} \frac{I_{R}\left(y,-45^{\circ}\right)}{I_{T}\left(y,-45^{\circ}\right)}}
\end{aligned}
$$


Atmos. Meas. Tech. Discuss., doi:10.5194/amt-2015-337, 2016

Manuscript under review for journal Atmos. Meas. Tech.

Published: 2 February 2016

(c) Author(s) 2016. CC-BY 3.0 License.

(c) (i)

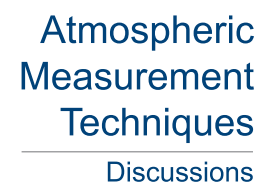

with $\mathrm{x}= \pm 45^{\circ} . \mathrm{I}_{R}$ and $\mathrm{I}_{T}$ are the collected signals for the transmitted and reflected components at $\pm 45^{\circ}$.

By using successive $\Delta 90^{\circ}$ calibration procedures at different placements of the calibrator in the optical chain, it is possible to assess how optical components are affecting the derived lidar depolarization products (diattenuation effects). This study will present the implementation of all these calibration methods, according to specific lidar setups in the EARLINET network. An extended comparison between different calibration methods, advantages and disadvantages, and possible error sources will also be discussed and analyzed.

\subsection{Determination of the gain ratio $\eta^{*}$ : experimental solutions}

\subsection{1 $\Delta 90^{\circ}$ mechanical rotation calibrator and HWP calibrator}

The first experimental setup for the lidar depolarization calibration is based on the calibrator module placed in front of the polarizing splitter ( $\mathrm{C} 1$ in Fig 3.a) or in front of the receiving optics ( $\mathrm{C} 2$ or $\mathrm{C} 2$ ' in Fig 3.a). The calibrator consists of a high precision mechanical rotator implementing rigid rotations of the PBS and PMTs at $+45^{\circ}$ and $-45^{\circ}$ with respect to the default measuring angle (considered the $0^{\circ}$ position) (Fig 3.c). By rotating the calibration module at $+45^{\circ}$ or $-45^{\circ}$, the light intensities in the transmitted and reflected paths are equalized independent of the atmospheric depolarization. The " $\Delta 90^{\circ}$ calibration" provides the gain ratio $\eta^{*} \Delta 90^{\circ}\left( \pm 45^{\circ}\right)$. E.g., the Athens EARLINET station (Kokkalis et al., 2013) operates depolarization lidars using a mechanical rotator in front of the PBS for the " $\Delta 90^{\circ}$ calibration" (Mamouri et al., 2012). Another approach with similar results as the $\Delta 90^{\circ}$ mechanical rotation calibrator is the use of a HWP to rotate the plane of polarization of the collected light to the desired angles (in this case $\pm 45^{\circ}$ ). This calibrator is called the $\Delta 90^{\circ} \mathrm{HWP}$ calibrator. The HWP rotator calibrator has the same effect and uses the same formulas as the mechanical rotator calibrator. In addition to the mechanical rotation calibrator, the HWP calibrator can also be placed in the emission block of the lidar system (C3 and C4 in Fig 3.a). This calibration method is used e.g. by the Munich (MULIS) (Freudenthaler et al., 2009) and Potenza (MUSA) lidar systems (Madonna et al., 2011). In both these systems the calibration module consists of a HWP rotator placed in front of the PBS, which rotates the plane of polarization of the light by $\pm 45^{\circ}$ with respect to the default polarization angle. The same type of calibrator can be also implemented by using a stepping motor rotation mount or a HWP mount which is placed in a holder with fixed and accurate positions at $0^{\circ}$ and $\pm 45^{\circ}$ (or multiple positions) (Fig 3.b).

An advantage when using this method is that measurements are not affected by the calibrator itself. The $\Delta 90^{\circ}$ mechanical rotation calibration introduces an angle error $(\Psi)$, always present in the measurement, whereas for cases where the $\Delta 90^{\circ} \mathrm{HWP}$ calibrator is removed after the calibration procedure, any errors introduced by the multi-angle polarizer calibrator or the HWP calibrator will not influence the measurements.

\subsection{2 $\Delta \mathbf{\Delta 0}^{\circ}$ polarizer rotator calibrator}

30 The third approach for the lidar depolarization calibration at $\Delta 90^{\circ}$ is the use of a linear polarizer. This type of calibrator can be implemented by using the mechanical rotating ring or the stepping motor rotation mount used for the optical rotator calibrator (Fig 3.b). The calibrator can be placed in front of the polarizing splitter $\left(C_{1}\right.$ in Fig 3.a) in front of the receiving optics $\left(C_{2}\right.$ 
Atmos. Meas. Tech. Discuss., doi:10.5194/amt-2015-337, 2016

Manuscript under review for journal Atmos. Meas. Tech.

Published: 2 February 2016

(c) Author(s) 2016. CC-BY 3.0 License.

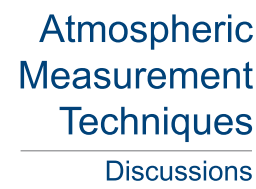

(c) (i)

or $C_{2}^{\prime}$ in Fig 3.a), or in the emission unit $\left(C_{3}\right.$ and $C_{4}$ in Fig 3.a). Several EARLINET lidar systems are using this calibration technique, in different versions. The cost-efficiency and simple design of this calibrator makes it easy to implement and also easy to use. Moreover, as it is a quite compact optical element, typically, it does not take much space to fit in the majority of the lidar optical chains. E.g., Leipzig and Evora lidar stations operate POLLY-XT multi-wavelength depolarization Raman lidar systems - (Althausen, 2013) - with cross and total depolarization channels at 532 and $355 \mathrm{~nm}$ (Leipzig) and 532nm (Evora)

(Fig 2.c). The calibration of the depolarization channels for these instruments is performed using the $\pm 45^{\circ}$ rotatable polarizer, placed in front of the detection optics, at the telescope's field stop. All experimental setups presented in this section are based on the " $\Delta 90^{\circ}$ calibration" procedure, therefore the methodology describing the assessment of the lidar depolarization calibration constant is similar for all calibrators described in the latter and further on. For all calibration procedures described in this study, the gain ratio can be derived from the geometric mean of the two consecutive measurements at $-45^{\circ}$ and $+45^{\circ}$ (Eq (31)).

For a general approach, the theoretical framework describing the assessment of the gain ratio for the lidar depolarization channels is described in details by Freudenthaler (2015).

\subsection{Assessment of the diattenuation parameter $D_{O}$}

The depolarization calibration procedures can also be used to investigate the effects of individual optical modules on the final lidar depolarization products (volume and particle linear depolarization ratio). This section will provide a method to measure the diattenuation value of an optical module placed between two calibrators. By comparing the calibration values obtained using the two calibrators, the investigator can assess the influence of the envisaged optical module on the depolarization products (the diattenuation parameter (Mattis et al., 2009)). Simulations performed by (Bravo-Aranda et al., 2015) shows that the effects of the diattenuation on depolarization products are highly significant. By using this method, we can correct the diattenuation effects for either the receiving optics (if the calibration modules are placed in front and after the receiving optics), the emitting optics (if the calibration modules are placed in front of the emitting optics and in front of the receiving optics) or both. The next section of the paper will show that once the diattenuation parameter is known, we can correct for its effect regardless of the calibrator's default position in the optical chain.

Several systems, such as lidars operated by Munich (MAISACH) (Freudenthaler et al., 2009), Granada (MULHACEN) (Guzman et al., 2013) or Bucharest stations (RALI) (Nemuc et al., 2013), have two or more depolarization calibration methods implemented. Both Granada and Bucharest stations run multi-wavelength Raman depolarization lidars, measuring two depolarization channels at $532 \mathrm{~nm}$ (one parallel and one perpendicular with respect to the plane of the linear polarised output of the laser) and a $90^{\circ}$ setup (Fig 2.a). The depolarization calibration setup consists of a set of two calibration modules/techniques, designed to evaluate the contribution of certain lidar sections on the final output.

The first calibrator is a mechanical rotator placed in front of the PBS - $C_{1}$ in Fig 3.a (for the $\Delta 90^{\circ}$ calibration) with a rotation accuracy better than $\pm 0.1^{\circ}$. The second calibrator consists of a linear polarizer mounted in front of the telescope's field-stop or in front of the receiving block $\left(\mathbf{M}_{O}\right)$ of the lidar system $\left(C_{2}\right.$ and $C^{\prime}{ }_{2}$ in Fig 3.a). A mechanical mount allows the polarizer to rotate by a fixed $22.5^{\circ} \pm 0.05^{\circ}$ rotating steps (Fig 3.b). By comparing the results obtained using the two calibrators, the 
Atmos. Meas. Tech. Discuss., doi:10.5194/amt-2015-337, 2016

Manuscript under review for journal Atmos. Meas. Tech.

Published: 2 February 2016

(c) Author(s) 2016. CC-BY 3.0 License.

(c) (i)

Atmospheric

Measurement

Techniques

Discussions

diattenuation of the optical elements in between $\left(\mathbf{M}_{O}\right)$ can be determined. It is important to take into account the diattenuation of all the optics before the calibrator used to perform the $\Delta 90^{\circ}$ calibration.

For lidar systems like the ones of Potenza and Munich, the diattenuation effect of the receiving optics $\left(\mathbf{M}_{O}\right)$ is known to be low due to a particular design of the optical module (optimized angles) and special manufactured optical components designed to reduce the diattenuation effects. In the case of Bucharest and Granada lidar systems, the influence of the receiving optics is known to have a greater impact on the depolarization products - see Table 1. This drawback can be corrected in the post measurement analysis, if the diattenuation effect of the considered optical module is already known. For the Bucharest and Granada lidar systems, the diattenuation of the receiving optics can be easily determined by assessing the ratio (Freudenthaler, 2015):

$10 \eta^{*}\left(D_{0}\right)=\frac{\eta_{\text {pol }}^{*}\left( \pm 45^{\circ}\right)}{\eta_{\text {rot }}^{*}\left( \pm 45^{\circ}\right)}=\frac{1+D_{0}}{1-D_{0}}$

leading to

$$
D_{O}=\frac{\eta_{\text {pol }}^{*}\left( \pm 45^{\circ}\right) / \eta_{\text {rot }}^{*}\left( \pm 45^{\circ}\right)-1}{\eta_{\text {pol }}^{*}\left( \pm 45^{\circ}\right) / \eta_{\text {rot }}^{*}\left( \pm 45^{\circ}\right)+1}
$$

Once $D_{O}$ is determined, the correction of the receiving optics diattenuation can be achieved using the general formula for the corrected linear depolarization ratio (Freudenthaler, 2015) (Eq.(16) (17)).

\subsection{Assessment of and correction for the laser rotation $\alpha$}

\subsubsection{Effects of $\alpha$ parameter on depolarization data - simulations}

One challenging topic when studying the influence of lidar optical modules on depolarization products is the assessment and correction of the rotation of the plane of polarization of the laser around the propagation axis or laser rotation with respect to the PBS $(\alpha)$. In order to assess the effects of $\alpha$ on the volume depolarization ratio and to find optimal solutions to correct the lidar signals, several simulations were performed for the Bucharest lidar system. The main goal of these simulations is to stress the effects on the input Stokes vector when it is rotated with $\alpha$ and it interacts with different optical media: emission optics (laser optics, high energy reflecting mirrors, beam expanders), the atmosphere (the $\mathbf{F}$ matrix) and the receiving optics (dichroic filters, short pass filters, mirrors, PBS). Fig 4.a-b shows simulations of calibrated signal ratio as a function of $\alpha$. The simulations demonstrate that for angles smaller than $3^{\circ}$, the effect on the calibrated signal ratio is negligible (Fig 4.b). The effects induced on the calibrated signal ratio increase dramatically for higher values of the angles (Fig 4.a). According to these simulations, the effects of $\alpha$ are also depending on the atmospheric depolarization: as atmospheric depolarization decreases, the dependence between the retrieved calibrated signal ratio and $\alpha$ is more significant. In real situations, the optical misalignment for $\alpha$ will not exceed $10-15^{\circ}$, but in order to present a complete dependency of the calibrated signal ratio, Fig 4.a shows the behavior of the latter for $\alpha$ ranging from $0^{\circ}$ to $180^{\circ}$. Simulated gain ratio $\left(\eta^{*}\right)$, obtained using the mechanical rotation in front of the PBS (Fig 4.c), show the dependency of the latter with atmospheric depolarization for $\alpha$ ranging from $0^{\circ}$ to $50^{\circ}$. This dependency 
Atmos. Meas. Tech. Discuss., doi:10.5194/amt-2015-337, 2016

Manuscript under review for journal Atmos. Meas. Tech.

Published: 2 February 2016

(c) Author(s) 2016. CC-BY 3.0 License.

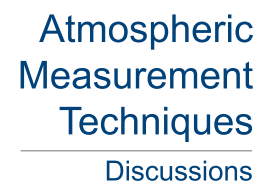

(c) (i)

alters the experimental retrieval of the gain ratio whenever $\alpha$ is considerable large $\left(\alpha>5^{\circ}\right)$. For this reason, a good practice would be to correct for the $\alpha$ angle before performing the calibration (experimental correction). The results show the effect of the $\alpha$ angle on the final depolarization products, further strengthening the necessity to develop experimental methods to assess and correct for this parameter. The results reinforce the hypothesis of having a complete assessment of the systematic errors for lidar depolarization products. See (Bravo-Aranda et al., 2015) for further details regarding the lidar polarizing sensitivity.

\subsubsection{Assessment of $\alpha$ parameter}

In order to determine $\alpha$, we apply the same principles as for assessing the calibrator rotation angle $-\varepsilon$ for the $\Delta 90^{\circ}$ polarizer rotator calibrator. In the case of the mechanical rotation calibrator, for the assessment of $\mathrm{Y}$ we need to perform a $\pm 45^{\circ}$ calibration measurement. When using the $\Delta 90^{\circ} \mathrm{HWP}$ calibrator for the assessment of $\alpha$, an extra procedure is required to determine the zero position of the calibrator with respect to the PBS (to reduce the $\varepsilon$ angle). This extra procedure is performed by using a polarizer calibrator prior to the HWP calibrator. In case the HWP calibrator is placed in front of the PBS, the polarizer calibrator could be placed in front of the receiving optics (or in front of the HWP). The first step is to minimize the $\varepsilon$ angle of the polarizer according with section 3.1. The next step is to insert the HWP calibrator in front of the PBS, while the polarizer is kept at the minimum $\varepsilon$ angle and to minimize the angle of the HWP with respect to the polariser position. The $\alpha$ assessment is performed after having removed the polarizer calibrator. The $\mathrm{Y}$ and $\alpha$ parameters are determined by using Eqs (35) and (36) respectively..

$$
\begin{aligned}
& Y(\alpha, K)=\frac{\eta_{p o l}^{*}\left(y,+45^{\circ}, \alpha, K\right)-\eta_{p o l}^{*}\left(y,-45^{\circ}, \alpha, K\right)}{\eta_{p o l}^{*}\left(y,+45^{\circ}, \alpha, K\right)+\eta_{p o l}^{*}\left(y,-45^{\circ}, \alpha, K\right)} \\
& =\frac{2 K s_{2 \alpha}}{1+K^{2} s_{2 \alpha}^{2}}
\end{aligned}
$$

$$
\alpha=\frac{1}{2} \arcsin \left[\frac{1}{K} \tan \left(\frac{\arcsin (Y(\alpha, K))}{2}\right)\right]
$$

Simulations in Fig 5.a-b show that, for a fixed value of $\alpha$, there is a strong dependency between $\mathrm{Y}$ and two important parameters: the polarization parameter of the atmospheric volume and the diattenuation parameter. The dependency of $\mathrm{Y}$ from the polarization parameter of the atmosphere does not affect the assessment of $\alpha$ drastically, since all the retrievals are performed in an aerosol free height, where the atmospheric depolarization is minimal. Although the simulations reveal a notable link between $\mathrm{Y}$ and the latter parameters, this dependency becomes negligible as the $\alpha$ value decreases. This particularity allows a highly accurate experimental correction of $\alpha$ by applying an iterative procedure: after the first iteration (first $\alpha$ assessment and correction), the effects of the polarization parameter of the atmospheric volume (atmospheric depolarization) and the diattenuation on the second $\alpha$ assessment are decreased and the correction becomes more and more accurate. The second iteration is performed for smaller $\alpha$ values, therefore having a better accuracy. After several iterations, the retrieved $\alpha$ value will be zero. 
Atmos. Meas. Tech. Discuss., doi:10.5194/amt-2015-337, 2016

Manuscript under review for journal Atmos. Meas. Tech.

Published: 2 February 2016

(c) Author(s) 2016. CC-BY 3.0 License.

(c) (i)

\author{
Atmospheric \\ Measurement \\ Techniques \\ Discussions
}

\subsubsection{Correction for the $\alpha$ parameter}

The experimental correction of $\alpha(\mathrm{Y})$ can be performed either by rotating the PBS in the WSU (without or together with the receiving optics) or by rotating the plane of polarization of the collected light using a HWP placed in front of the PBS or in front of the receiving optics (in the case of one channel lidar systems or systems with separate optics for the depolarization

5 channels).

Once the final $\alpha(\mathrm{Y})$ value is retrieved according to the procedure described in the previous section, the corresponding analytical correction should be used to correct for the rotational misalignments of the laser. This can be done by using the equation for the volume linear depolarisation ratio of the atmospheric volume (Eq.(17) (18)). E.g. for the $90^{\circ}$ detection setup (for the Bucharest RALI lidar system), the atmospheric volume linear depolarisation ratio is expressed by:

$10 \delta=\frac{n_{1}-\delta^{*} n_{2}}{\delta^{*} n_{3}-n_{4}}$

with

$n_{1}=\left(1+D_{0} c_{2 \alpha}\right)-D_{R}\left(D_{0}+c_{2 \alpha}\right)$

$n_{2}=\left(1+D_{0} c_{2 \alpha}\right)-D_{T}\left(D_{0}+c_{2 \alpha}\right)$

15

$n_{3}=\left(1-D_{0} c_{2 \alpha}\right)-D_{T}\left(D_{0}-c_{2 \alpha}\right)$

$n_{4}=\left(1-D_{0} c_{2 \alpha}\right)-D_{R}\left(D_{0}-c_{2 \alpha}\right)$

where $\mathrm{c}_{2 \alpha}=\cos (2 \alpha)$. According to simulations (Fig 5.c), the uncertainties of the analytical correction for $\alpha$ can reach up to $25 \%$

for a $10^{\circ}$ initial offset and a maximum diattenuation value of 0.25 .

\section{Correction of $\alpha$ in front of the PBS:}

For lidar systems designed to use the mechanical rotation calibrator in front of the PBS, the most efficient technique designed to correct for $\alpha$ is to measure it's value and turn the PBS according to the measured offset value of $\alpha$.

Equivalent results can be obtained also by rotating the laser polarization plane by means of a HWP module placed in front of the PBS. For the $\alpha$ correction, the compensation angle of the correction module will be considered $\varepsilon^{\prime}$. Simulations of the calibrated signal ratio corrected with $\varepsilon^{\prime}$ are presented in Fig 6.a (for $\left.\alpha=-\varepsilon^{\prime}\right)$. The results show that for $\varepsilon^{\prime}=10^{\circ}$, the correction error is reaching 3\% from the absolute value of the calibrated signal ratio. This error is most probably caused by the method itself: when using the mechanical rotation or HWP rotation in front of the PBS, we compensate for $\alpha$ after the receiving optics 
Atmos. Meas. Tech. Discuss., doi:10.5194/amt-2015-337, 2016

Manuscript under review for journal Atmos. Meas. Tech.

Published: 2 February 2016

(c) Author(s) 2016. CC-BY 3.0 License.

(c) (i)

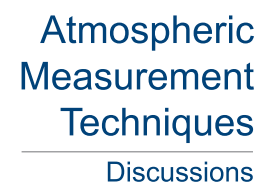

$\left(\mathbf{M}_{O}\right)$. The effects introduced by $\alpha$ in the receiving optics, as the collected backscattered light is guided toward the PBS, are not removed by this correction. We must stress that in order to perform a comprehensive simulation, the diattenuation parameter of the receiving optics was considered 0.23 (measured diattenuation for the Bucharest RALI lidar system - Table (1)) and the atmospheric depolarization 0.05 (since higher values for the atmospheric depolarization will not drastically alter the correction error).

\section{Correction of $\alpha$ in front of the receiving optics:}

For lidar systems designed to use a mechanical rotation calibrator in front of the receiving optics, the optimal technique designed to correct for $\alpha$ is to measure its value and then to rotate the receiving optics accordingly. This technique is considered the best since by rotating both the receiving optics and the PBS, all the effects introduced by $\alpha$ in the receiving optics are removed.

For the case of a one wavelength lidar system (or distinct receiving unit for the depolarization channels), a HWP calibrator placed in front of the receiving optics can also be used to correct for $\alpha$ (similar with lidar systems having separate emission axes for different wavelengths - the correction will be performed at the emission). In case of a multi-wavelength lidar system (with one emission axes), the angle correction would be applied to all channels, changing the plane of polarization for all collected wavelengths according to the individual wavelength. In cases where the calibrator (used in this case for the correction of $\alpha$ ) is placed in front of the receiving optics, the simulations show that the linear depolarization ratio error is less than $0.1 \%$ for a $10^{\circ}$ offset - Fig 6.b. One drawback when using this type of correction is the uncertainty related to the rotation precision of the calibrator modules. We assume that for a common HWP support or mechanical rotator, the rotation precision is around $1^{\circ}$.

Simulations for $\delta^{*}$ in correspondence of several rotation precisions of the $\alpha$ angle are shown in Fig. 6.a. All simulations refer to the case of the calibrator placed in front of the receiving optics (e.g. for $1^{\circ}$ correction error, we simulated the absolute value offset between $\varepsilon^{\prime}$ and $\alpha$ to be exactly $1^{\circ}$ ). An offset of $2 \%$ compared to the optimal correction value is obtained for $1^{\circ}$ rotation error of the calibrator module. If we consider a $2.5^{\circ}$ rotation error, the offset is around $10 \%$ compared to the real correction value. The simulations demonstrate that the rotation uncertainty will not drastically alter the corrections as long as the uncertainty will not exceed $1-2^{\circ}$.

Further on, in order to perform comparisons between corrected and not corrected lidar profiles, we will only consider the post measurement analytical correction for $\alpha$. In doing that, we assume the assessment of $\alpha$ is so accurate to allow analytical correction as reliable as the ones obtained by using a calibrator in front of the PBS.

\section{Results and Discussions}

Numerous optical components inside the lidar's emission and receiving units can lead to large systematic errors of the atmospheric depolarization values. Methods designed to assess and correct instrumental effects on the depolarization channels are constantly under development. The volume linear depolarization ratio profiles show significant improvements when reliable and accurate depolarization calibration techniques are used. The impact of the calibration is mostly visible in the aerosol free region, where the rather low molecular contribution is usually added to the systematic error of the instruments. The particle 
Atmos. Meas. Tech. Discuss., doi:10.5194/amt-2015-337, 2016

Manuscript under review for journal Atmos. Meas. Tech.

Published: 2 February 2016

(c) Author(s) 2016. CC-BY 3.0 License.

(c) (i)

Atmospheric

Measurement

Techniques

Discussions

linear depolarization ratio profiles are also improved by the calibration, although in this case, the uncertainties also include the contribution of the aerosol backscatter coefficient (Freudenthaler et al., 2009).

\subsection{The gain ratio $\eta^{*}$}

The gain ratio and diattenuation values for several calibration methods are presented in Table 1. $\eta^{*}$ pol represents the gain ratio

5 value retrieved using the $\Delta 90^{\circ}$ polarizer rotator calibrator placed in front of the receiving optics and $\eta^{*}{ }_{r o t}$ represents the gain ratio value retrieved using either the $\Delta 90^{\circ} \mathrm{HWP}$ calibrator or the $\Delta 90^{\circ}$ mechanical rotation calibrator, placed in front of the PBS.

\subsection{The diattenuation parameter $\mathrm{D}_{0}$}

The diattenuation parameter for the Potenza and Munich systems show values that are one order of magnitude lower than the rest of the lidar systems. These values are the result of a special optical design of the WSU (Freudenthaler et al., 2009), combined with custom made optics specially designed to have low diattenuation values. The errors associated with each value in the table are determined by using the standard deviation of consecutive calibrations performed over limited time periods or calculated over the calibration interval for one single calibration measurement. Fig 7.a-b shows the gain ratio retrieved using two experimental techniques for Granada and Bucharest systems. The difference between the $\eta^{*}{ }_{p o l}$ and $\eta^{*}{ }_{r o t}$ represents the effect of the receiving optics diattenuation parameter $\left(D_{0}\right)$ on the depolarization value. Fig 7.a-b illustrates the height dependence of the gain ratio, retrieved by using two depolarization calibration modules. The results show that for the presented altitudes, the height dependence of the calibration value is not significant (for neither the Bucharest nor Granada lidar systems). For the Bucharest system, the gain ratio profiles from 1 to $3.5 \mathrm{~km}$ show higher stability for the mechanical rotator retrievals $\left(\eta^{*}{ }_{r o t}\right)$ in respect to the polarizer rotation retrievals $\left(\eta^{*}{ }_{p o l}\right)$. This stability difference could be caused by the presence of 20 atmospheric layers with higher depolarization signature in the investigated range, changing rapidly with time. For the Granada system, the profiles show the same stability for both $\eta^{*}{ }_{p o l}$ and $\eta^{*}{ }_{r o t}$. The height dependence for the gain ratio could be used as a good indicator of potential problems in the optical layout of the lidar system.

\subsection{Rotation of the plane of polarisation of the laser $(\alpha)$}

One of the parameters that has a significant impact on depolarization products is the rotation of the plane of polarisation of the laser with respect to the PBS: $\alpha(\mathrm{Y})$. According to numerical simulations already presented, correction of the $\alpha$ parameter can be achieved by using the mechanical rotator, a HWP placed in front of the PBS or in front of the receiving optics or a post measurement analytical correction once the $\alpha$ parameter is known. Fig 7.c shows results of the assessment and correction of the $\alpha$ parameter for the Bucharest system, using the mechanical rotator in front of the PBS. The correction is performed with the iterative procedure described in the previous sections, by rotating the linear analyzer (PBS) in accordance with measured $\alpha$ values. The values show that measured $\alpha$ reaches a value equal to $-0.04^{\circ}$ after four iterations. The experimental results are in good agreement with the theoretical simulations from the methodology. The impact of the $\alpha$ correction on the depolarization 
Atmos. Meas. Tech. Discuss., doi:10.5194/amt-2015-337, 2016

Manuscript under review for journal Atmos. Meas. Tech.

Published: 2 February 2016

(c) Author(s) 2016. CC-BY 3.0 License.

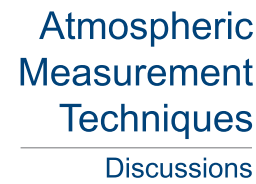

(c) (P)

profiles can be easily emphasized for the post measurement analytical correction, presented in section 3.4.2. Fig 8.a-c shows an example of volume and particle linear depolarization ratios from $26^{\text {th }}$ of September 2013, measured by the Bucharest lidar system RALI (Nemuc et al., 2013). The elastic range corrected time series show stable layers in the lower troposphere and ice clouds above $8 \mathrm{~km}$ - Fig 8.a - red vertical lines show the averaged time period considered for the calculation of the volume linear depolarization profiles. The non-calibrated volume linear depolarization profile show values reaching up to 0.27 in the ice cloud and 0.12 in the free troposphere (Fig 8.b). The calibrated profile ( $\eta^{*}{ }_{p o l}$ corrected, no $\alpha$ correction) shows lower values in the free troposphere and values reaching 0.42 in the ice cloud. After $\alpha$ correction, the volume linear depolarization values reach 0.40 in the cloud and close to the molecular in the free troposphere (Sassen et al., 2007), (Sassen, 2005). Table 2 shows non-calibrated and calibrated ( $\alpha$ corrected) volume linear depolarization retrievals in two cases: in the cloud layer and in the free troposphere. For the free troposphere, the initial values are over 10 times larger than for the calibrated profiles. Values for the calibrated profiles with and without alpha correction show a small difference in the cloud layer (0.02), but larger differences are observed in the free troposphere, where the volume linear depolarization is of the same order of magnitude with the $\alpha(\mathrm{Y})$ corrections. The statistical uncertainties of the not-corrected volume depolarization profile are larger in comparison with uncertainties characterizing the calibrated $\alpha$ corrected profile. The uncertainties associated with the determination of instrument parameters (IP) (linked only with systematic retrieval errors) can be neglected once the parameter is measured and the corresponding corrections are applied (diattenuation, $\alpha, \eta$ ). For not-corrected profiles, the unknown IP values and the related uncertainties are large, leading to big error bars in the final depolarization products. According to Fig 8.b, the associated error bars show a significant improvement: from 0.1 for the "not corrected data" profile, to 0.06 for the "no $\alpha$ correction" profile, to 0.005 for the "corrected data" profile (for altitudes reaching $8 \mathrm{~km}$ ). For the assessment of the systematic errors, no retardation effects were considered.

\subsection{Selected cases of calibrated profiles in the EARLINET framework}

In order to emphasize the importance of the depolarization calibration for the long range transport and aerosol typing studies, several experimental results obtained using calibrated depolarization lidar instruments from different EARLINET stations are presented and discussed. The data shows only the corrected depolarization profiles since many lidar systems provide automatic or hardware corrected depolarization products. The purpose of this section is to present the importance of calibrated depolarization lidar products in long range transport studies and uncorrected profiles are not required in this section. The measurements are performed on an extended time scale, so that statistical noise becomes negligible (vertical red delimiters over the range corrected signals - RCS - mark the averaged periods). Fig 9.a-c shows a case of multiple layered atmosphere over the Bucharest site on $3^{\text {rd }}$ of May 2012. The range corrected time series show a well defined PBL (Planetary Boundary Layer) up to $2.7 \mathrm{~km}$ altitude, and several layers in the free troposphere. The first layer, ranging from 5 to $5.8 \mathrm{~km}$, has a volume linear depolarization of 0.02 and particle linear depolarization ratio of 0.05 with a faint signal in the backscatter. The second and third layers, more visible in the backscattered signals, have a particle linear depolarization ratio of 0.22 and 0.19 respectively. Within the aerosol free regions, the volume linear depolarization ratio drops down to the molecular depolarization (Behrendt and Nakamura, 2002), a good indicator that the calibration procedures are applied correctly. The back-trajectory model (Draxler 
Atmos. Meas. Tech. Discuss., doi:10.5194/amt-2015-337, 2016

Manuscript under review for journal Atmos. Meas. Tech.

Published: 2 February 2016

(c) Author(s) 2016. CC-BY 3.0 License.

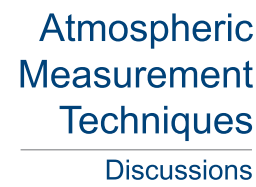

(c) (P)

et al., 2014; Rolph et al., 2014) shows a complex case of air masses arriving over Bucharest from different sources (Fig 9.d). The air mass related to the first layer is descending from Northern Europe though a circular motion. The measured particle linear depolarization ratio within this layer (0.05) together with the value of 50sr obtained at 532nm for the extinction-tobackscatter ratio, are sufficient to presume that the layer is mostly composed of industrial or smoke aerosols. According to the back-trajectories analysis, the aerosol layer detected above $7 \mathrm{~km}$ comes from the Arabic Peninsula, North of the Arabic desert. The air mass origin and the particle linear depolarization values indicate that the aerosol layer at the specified altitudes is composed of aged mineral dust. The higher layer, ranging from 8.7 to $9.6 \mathrm{~km}$ has a Saharan origin (Fig 9.d). For this layer, the particle linear depolarization ratio has a maximum value of 0.19 . This indicates that the aged dust is probably mixed with continental polluted aerosol as a result of the six days transport.

Measurements performed on the same date by the Athens lidar system reveal a highly turbulent atmosphere up to $4 \mathrm{~km}$ (Fig 10.a). Although the RCS shows the presence of multiple layers, the calibrated volume and particle linear depolarization profiles indicate only one distinct aerosol layer ranging from 3 to $4 \mathrm{~km}$ with a particle linear depolarization ratio of 0.06 . The particle linear depolarization values, together with the HYSPLIT back-trajectories analysis, indicate the presence of continental polluted aerosol in the air mass (Fig 10.b-d). Measurements performed using the Granada lidar system (Mulhacen) in July 2012 show the presence of a distinct layer between 2.5 and $5 \mathrm{~km}$ (Fig 11.a-c). The particle linear depolarization ratio shows high values in the aerosol layer (0.223) and levels close to the molecular depolarization in the aerosol free region. The back trajectories model indicates that the corresponding air mass originates in Northern Sahara, and was transported for several days over NW Africa and the Atlantic ocean (Fig 11.d). According to the back trajectories and the particle linear depolarization values retrieved for these altitudes, the aerosol present in the air mass is probably aged mineral dust.

The RCS from the Potenza lidar system (MUSA) for $6^{\text {th }}$ of August 2012 presents a strong aerosol intrusion above the PBL (Fig 12.a). The non-homogenous layer between 2 and $5 \mathrm{~km}$ has a volume linear depolarization ratio reaching 0.18 and the particle linear depolarization ratio around 0.31 (Fig 12.b-c), indicating a case of pure mineral aerosol. The back-trajectory model shows that the air-masses originate from the Sahara regions, being transported for several days over the desert and the Atlantic ocean (Fig 12.d). Although the trajectories are somehow similar with the ones from the previous case (Mulhacen Granada measurements) and also the origin of aerosol layers could be considered to be from the same region of Sahara, the values retrieved for the particle linear depolarization ratio suggest a difference in the type of the detected particles (mineral dust mixed with continental or marine for Granada system, pure dust for Potenza system). According to that, an analysis including also the particle linear depolarization ratio can provide information regarding not only the nature of the aerosol layers, but also about the age and purity of aerosol particles (Tesche et al., 2011; Gross et al., 2011; Muller et al., 2003).

The case selected for the Munich lidar system (Maisach) refers to the Eyjafjallajökul volcanic eruption occurred during April 2010. The range corrected time series (Fig.13.a) highlight a distinct layer ranging from 2.3 up to $2.8 \mathrm{~km}$. The one hour mean value of the particle (volume) linear depolarization ratio measured in this layer is $0.38(0.34)$. The values are consistent with typical values retrieved for fresh volcanic ash (Hervo et al., 2012; Hogan et al., 2012; Pappalardo et al., 2012). The presence of fresh volcanic ash is also confirmed by the back-trajectories: air masses originating from Southern Iceland, very close to the Eyjafjallajökul Volcano, detected over Munich 48 hour after the eruption (Fig 13.d). 
Atmos. Meas. Tech. Discuss., doi:10.5194/amt-2015-337, 2016

Manuscript under review for journal Atmos. Meas. Tech.

Published: 2 February 2016

(c) Author(s) 2016. CC-BY 3.0 License.

(c) (i)

$\begin{array}{r}\text { Atmospheric } \\ \text { Measurement } \\ \text { Techniques } \\ \hline \text { Discussions }\end{array}$

Measurements performed in Leipzig using the PollyXT lidar system on $20^{t h}$ of August 2012 highlight a distinct layer ranging between 2.5 and $5 \mathrm{~km}$ (Fig 14.a). The calibrated depolarization products show significantly high values at these specific altitudes. The volume linear depolarization ratio is reaching values of 0.14 within the layer and the particle linear depolarization ratio approaches values up to 0.25 (Fig 14.b-c). The back-trajectory analysis indicate air masses arriving from Northern Sahara, after having followed some convective developments over the African continent, with strong updrafts and downdrafts throughout the trajectory (Fig 14.d - blue line). The retrieved parameters are consistent with the presence of aged mineral dust.

The cases presented above emphasize the importance of calibrated depolarization lidar products in aerosol typing. All cases were selected in order to highlight different atmospheric layers and environmental conditions (fresh dust, aged dust, volcanic ash, continental polluted aerosol, for stable and convective atmospheric conditions). The associated errors were determined by each EARLINET station, according to their own internal error assessment procedures. For most cases, uncertainties related to the systematic errors for the calibrated volume linear depolarization profiles are within $0.01-0.02$ for all heights up to $8-9 \mathrm{~km}$. The larger uncertainties of the particle linear depolarization profiles with respect to the volume are mainly due to the backscatter profile, which is needed to perform the retrievals. The uncertainties related to the backscatter profiles are the result of additional assumptions required to perform the inversions (especially during daytime) - lidar ratio profile and calibration values (Nemuc et al., 2013; Kovalev and Eichinger, 2004). Although the statistical error is negligible (averaged profiles), statistical and systematic depolarization errors are included for some cases. Appendix B presents an example for the assessment of systematic errors related to the depolarization calibration modules.

\section{Conclusions}

This paper presents an extended analysis of various depolarization calibration techniques, specific to depolarization lidar systems within the EARLINET network. The calibration modules were analyzed in respect to two criteria: the type of the calibrator and it's placement inside the optical chain. Different schemes for assessing and correcting the rotation of the plane of polarization of the laser $(\alpha)$ are presented. A method to retrieve the effective diattenuation of the receiving optics is discussed and analyzed as well.

The two described calibration methods (calibrator in front of the PBS and the calibrator in front of the receiving optics) proved reliable as technical solutions for the " $\Delta 90^{\circ}$ calibration". The advantage when using the calibrator in front of the receiving optics is that depolarization products are also corrected for the influence of the receiving optics, while the methods that use the calibrator in front of the PBS allows to take into account only the influence of lidar modules after the calibrator, throughout the optical path. From experimental point of view, the primary design includes a mechanical rotator for the PBS, a HWP used to rotate the plane of polarization of the collected light and an extra polarizer, used to rotate according to the requirements of the calibration measurements. All calibration designs proved to be effective and the results showed significant improvements after the calibration procedures were applied. Among the several calibration schemes described in this study, the $\Delta 90^{\circ} \mathrm{HWP}$ calibrator in front of the receiving optics proved to be the most reliable. The advantages of this type of calibrator can be summarized as follows: effectiveness when implementing the calibrator - since it can be easily mounted in the field- 
Atmos. Meas. Tech. Discuss., doi:10.5194/amt-2015-337, 2016

Manuscript under review for journal Atmos. Meas. Tech.

Published: 2 February 2016

(c) Author(s) 2016. CC-BY 3.0 License.

(c) (i)

$\begin{array}{r}\text { Atmospheric } \\ \text { Measurement } \\ \text { Techniques } \\ \hline \text { Discussions }\end{array}$

stop of the telescope, cost efficient - the extra modules needed to mount the calibrator are cheap and easy to use. The output of the calibrator includes the contribution of the receiving optics, and errors related to the calibrator itself do not influence the measurements since the modules will be removed after performing the calibration. A drawback of using this calibrator is related to the optical setup of the lidar receiving unit, because the layout of the receiving optics could obstruct the access to the telescope's field-stop, resulting in difficulties when performing the actual calibration.

Second part of the study was related to the impact of the rotation of the plane of polarization of the laser around the propagation axis $(\alpha)$ with respect to the PBS. The effects of $\alpha$ on the final depolarization products and the efficiency of two correction schemes were discussed and analyzed: rotation of the linear analyzer in the WSU and rotation of the collected backscattered light by means of a HWP placed in front of the receiving optics and PBS. The efficiency of the second technique is significantly better, and the errors associated with the correction procedures are much lower than the ones obtained by rotating the PBS. The drawback of the HWP in front of the receiving optics is related to the number of lidar systems it can be applied to: single wavelength depolarization lidars or systems having a distinct receiving unit for the depolarization channels or distinct emission axes.

The improvements in the depolarization values retrieved for the aerosol layers and ice clouds (where the particle depolarization reaches typical values up to $0.35-0.45 \pm 0.02$ ) as well as in the free troposphere (where the volume linear depolarization decreases down to values lower than $0.005 \pm 0.01$ ), are of significant importance when the depolarization calibration and $\alpha$ corrections are used. The combination of multiple calibration methods proved to be useful in assessing the diattenuation parameter of the receiving optics. Case studies presented in this paper illustrate significant improvements of the depolarization lidar products for all selected lidar stations. The calibrated particle linear depolarization ratio shows values greater than $0.40 \pm 0.05$ in cirrus clouds, $0.23 \pm 0.02$ for transported dust, $0.31 \pm 0.04$ for fresh dust, $0.38 \pm 0.01$ for volcanic ash and $0.05 \pm 0.04$ for continental pollution. In the aerosol free regions, where the impact of the calibration procedures is obvious, the volume linear depolarization ratio goes down to the molecular level (Behrendt and Nakamura, 2002).

Our study emphasizes the need of implementing calibration and correction procedures for the retrieval of depolarization products, homogeneously for the entire EARLINET network. On the other side it is also fundamental to adapt the selected procedures to the different types of lidar systems operating within EALRINET.

\section{Appendix A: Acronyms and shortcuts}

a polarization parameter of the atmospheric volume

$a_{L} \quad$ polarization parameter of the light beam leaving the laser

$\alpha \quad$ rotation of the plane of polarization of the laser around the propagation axis (laser rotation)

$\beta \quad$ rotation of the emitter optics around the propagation axis

$\gamma \quad$ rotation of the receiver optics around the propagation axis 
Atmos. Meas. Tech. Discuss., doi:10.5194/amt-2015-337, 2016

Manuscript under review for journal Atmos. Meas. Tech.

Published: 2 February 2016

(c) Author(s) 2016. CC-BY 3.0 License.

(c) (i)

\section{Atmospheric \\ Measurement \\ Techniques \\ Discussions}

$c_{\varepsilon} \quad \cos (\varepsilon)$

$s_{\varepsilon} \quad \sin (\varepsilon)$

$\varepsilon \quad$ error angle of the $\Delta 90^{\circ}$ calibration setup

$\psi \quad$ rotation of the calibrator around the light propagation axis

$\delta \quad$ linear depolarization ration of the atmospheric scattering volume, volume linear depolarization ratio (LDR)

$\delta^{*} \quad$ calibrated signal ratio including cross talk and alignment errors

$\delta^{p} \quad$ particle linear depolarization ratio (PDR)

D diattenuation parameter

$\eta_{T, R} \quad$ electronic amplification of individual transmitted/reflected channels

$\eta \quad$ calibration factor including only the electronic amplification and the optical diattenuation of the polarizing beam splitter

$\eta^{*} \quad$ gain ratio of the polarization channels, the calibration factor including the cross talk from optics before the polarizing beam splitter and from system alignment errors

$\mathbf{M}_{s} \quad$ Muller matrix of the polarizing beam splitter

$\mathbf{M}_{T, R} \quad$ Muller matrix in the transmission and reflection path

$T_{S} \quad$ transmission of matrix $\mathbf{M}_{S}$ for unpolarised light

$T^{p, s}$

$R^{p, s} \quad$ intensity transmission and reflection coefficients of the polarizing beam splitter for parallel and perpendicular linearly polarised light with respect to the plane of incidence

F Muller matrix of the atmospheric scattering volume in backscattering direction

y optical setup type for the cross and parallel lidar configuration. For $y=-1$ we have the $90^{\circ}$ setup and for $\mathrm{y}=1$ we have the $0^{\circ}$ setup (see Figure.2).

$\Delta \quad$ differential phase shift of the $\mathrm{p}$ and s polarised light

$\phi^{p, s} \quad$ phase of the $\mathrm{p}$ and s polarised light

Appendix B: Assessment of systematic errors for uncertainties related to the depolarization calibration modules: $9^{\circ}$ detection setup

If we consider a cross and parallel detection design, a $90^{\circ}$ detection setup, $\mathrm{D}_{0}=0, \alpha=0$ and $a_{L}=1$, using Eq.(17) (18) we obtain 5 a simplified form for the volume linear depolarization ratio:

$\delta=\frac{T^{*} T_{R}^{s}-\delta^{*} T_{T}^{s}}{\delta^{*} T_{T}^{p}-T^{*} T_{R}^{p}}$ 
Atmos. Meas. Tech. Discuss., doi:10.5194/amt-2015-337, 2016

Manuscript under review for journal Atmos. Meas. Tech.

Published: 2 February 2016

(c) Author(s) 2016. CC-BY 3.0 License.

(c) (i)

with

$T^{*}=\frac{T_{T}}{T_{R}}=\frac{T_{T}^{p}+T_{T}^{s}}{T_{R}^{p}+T_{R}^{s}}$

and

$D_{T / R}=\frac{T_{T / R}^{p}-T_{T / R}^{s}}{T_{T / R}^{p}+T_{T / R}^{s}}$

5 from eq B1 and B2 we have

$\delta=\frac{T_{R}^{s}\left(T_{T}^{p}+T_{T}^{s}\right)-\delta^{*} T_{T}^{s}\left(T_{R}^{p}+T_{R}^{s}\right)}{\delta^{*} T_{T}^{p}\left(T_{R}^{p}+T_{R}^{s}\right)-T_{R}^{p}\left(T_{T}^{p}+T_{T}^{s}\right)}$

The systematic error associated to $\delta$ is calculated using

$$
\begin{array}{r}
\Delta \delta=\left|\frac{\delta \delta}{\delta T_{R}^{s}}\right| \Delta T_{R}^{s}+\left|\frac{\delta \delta}{\delta T_{R}^{p}}\right| \Delta T_{R}^{p}+\left|\frac{\delta \delta}{\delta T_{T}^{s}}\right| \Delta T_{T}^{s}+ \\
+\left|\frac{\delta \delta}{\delta T_{T}^{p}}\right| \Delta T_{T}^{p}+\left|\frac{\delta \delta}{\delta \delta^{*}}\right| \Delta \delta^{*}
\end{array}
$$

10

for the signal ratio we have:

$\delta^{*}=\frac{1}{\eta} \cdot \frac{I_{R}}{I_{T}}$

and the associated systematic error is

$\Delta \delta^{*}=\left|\frac{\delta \delta^{*}}{\delta I_{R}}\right| \cdot \Delta I_{R}+\left|\frac{\delta \delta^{*}}{\delta I_{T}}\right| \cdot \Delta I_{T}+\left|\frac{\delta \delta^{*}}{\delta \eta}\right| \cdot \Delta \eta$

For the assessment of $\Delta \eta$ we use:

$15 \eta=\frac{I_{R}\left( \pm 45^{\circ}\right)}{I_{T}\left( \pm 45^{\circ}\right)}$

If we consider errors associated to $\eta_{S}, D_{S}, D_{O}$, and $T_{S}$ to be negligible, the error for $\eta$ can be assessed by using:

$\Delta \eta=\left|\frac{\delta \eta}{\delta \varepsilon}\right| \cdot \Delta \varepsilon$

For assessing the particle linear depolarization ratio we are using the formula presented in (Freudenthaler et al., 2009). The formula includes the molecular linear depolarization ratio, the volume linear depolarization ratio and the backscatter ratio (R).

20 The error related to the particle linear depolarization ratio is calculated using the backscatter ratio $\mathrm{R}$ :

$\delta^{P}=\frac{\left(1+\delta^{m}\right) \delta^{v} R-\left(1+\delta^{v}\right) \delta^{m}}{\left(1+\delta^{m}\right) R-\left(1+\delta^{v}\right)}$ 
Atmos. Meas. Tech. Discuss., doi:10.5194/amt-2015-337, 2016

Manuscript under review for journal Atmos. Meas. Tech.

Published: 2 February 2016

(c) Author(s) 2016. CC-BY 3.0 License.

(c) (i)

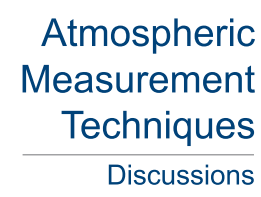

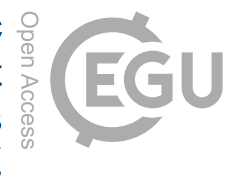

$R=\frac{\beta^{m}+\beta^{p}}{\beta^{m}}$

is the ratio between the total backscatter coefficient and the molecular component. The error for the particle linear depolarization ratio can be determined by using its formula:

$\Delta \delta^{P}=\left|\frac{d \delta^{p}}{d R} R\right|+\left|\frac{d \delta^{p}}{d \delta} \delta\right|$

5 According to (Freudenthaler et al., 2009), the backscatter coefficient is derived from the total signal using Fernald-Klett inversion, for which a calibration value at a reference range is needed. The range dependent lidar ratio is also needed for this inversion. E.g., for the daytime measurements performed using the RALI lidar system we used a $20 \%$ uncertainty for the calibration value and $\pm 10 \mathrm{sr}$ for the lidar ratio (which was usually considered to be $50 \mathrm{sr}$ ). Although the statistical noise is usually small compared with the systematic errors (for the purpose of the paper the measurements are performed so that the statistical noise is small), the error introduced by the noise can add up during daytime measurements, when the background light is high. For most of the presented data (Bucharest, Granada and others), the uncertainties related with this errors are added to the total systematic error. This error analysis can be further applied to the $0^{\circ}$ detection setup by replacing the corresponding formula for the volume linear depolarization ratio.

Acknowledgement. This work was supported by the European Community's FP7-INFRASTRUCTURES-2010-1 under grant no. 262254 -

ACTRIS and by a grant of the STAR-ESA Programme 55/2013-CARESSE, Grant from Portuguese Science Foundation (FCT) SFRH/BPD/81132/2011. 
Atmos. Meas. Tech. Discuss., doi:10.5194/amt-2015-337, 2016

Manuscript under review for journal Atmos. Meas. Tech.

Published: 2 February 2016

(c) Author(s) 2016. CC-BY 3.0 License.
Atmospheric

Measurement

Techniques

Discussions

\section{References}

The EARLINET publishing group 2000-2010, Adam, M., Alados-Arboledas, L., Althausen, D., Amiridis, V., Amodeo, A., Ansmann, A., Apituley, A., Arshinov, Y., Balis, D., Belegante, L., Bobrovnikov, S., Boselli, A., Bravo-Aranda, J. A., Bosenberg, J., Carstea, E., Chaikovsky, A., Comeron, A., D’Amico, G., Daou, D., Dreischuh, T., Engelmann, R., Finger, F., Freudenthaler, V., Garcia-Vizcaino,

D., Garcia, A. J. F., Geiss, A., Giannakaki, E., Giehl, H., Giunta, A., De Graaf, M., Granados-Munoz, M. J., Grein, M., Grigorov, I., Gross, S., Gruening, C., Guerrero-Rascado, J. L., Haeffelin, M., Hayek, T., Iarlori, M., Kanitz, T., Kokkalis, P., Linne, H., Madonna, F., Mamouriat, R.-E., Matthias, V., Mattis, I., Menendez, F. M., Mitev, V., Mona, L., Morille, Y., Munoz, C., Muller, A., Muller, D., Navas-Guzman, F., Nemuc, A., Nicolae, D., Pandolfi, M., Papayannis, A., Pappalardo, G., Pelon, J., Perrone, M. R., Pietruczuk, A., Pisani, G., Potma, C., Preissler, J., Pujadas, M., Putaud, J., Radu, C., Ravetta, F., Reigert, A., Rizi, V., Rocadenbosch, F., Rodriguez, A., Sauvage, L., Schmidt, J., Schnell, F., Schwarz, A., Seifert, P., Serikov, I., Sicard, M., Silva, A. M., Simeonov, V., Siomos, N., Sirch, T., Spinelli, N., Stoyanov, D., Talianu, C., Tesche, M., De Tomasi, F., Trickl, T., Vaughan, G., Volten, H., Wagner, F., Wandinger, U., Wang, X., Wiegner, M. and Wilson, K. M.: EARLINET all observations (2000-2010), World Data Centre for Climate (WDCC), doi:http://dx.doi.org/10.1594/WDCC/EN_all_measurements_2000-2010,2014a.

The EARLINET publishing group 2000-2010, Adam, M., Alados-Arboledas, L., Althausen, D., Amiridis, V., Amodeo, A., Ansmann,

A., Apituley, A., Arshinov, Y., Balis, D., Belegante, L., Bobrovnikov, S., Boselli, A., Bravo-Aranda, J. A., Bosenberg, J., Carstea, E., Chaikovsky, A., Comeron, A., D’Amico, G., Daou, D., Dreischuh, T., Engelmann, R., Finger, F., Freudenthaler, V., Garcia-Vizcaino, D., Garcia, A. J. F., Geiss, A., Giannakaki, E., Giehl, H., Giunta, A., De Graaf, M., Granados-Munoz, M. J., Grein, M., Grigorov, I., Gross, S., Gruening, C., Guerrero-Rascado, J. L., Haeffelin, M., Hayek, T., Iarlori, M., Kanitz, T., Kokkalis, P., Linne, H., Madonna, F., Mamouriat, R.-E., Matthias, V., Mattis, I., Menendez, F. M., Mitev, V., Mona, L., Morille, Y., Munoz, C., Muller, A., Muller, D., Navas-Guzman, F., Nemuc, A., Nicolae, D., Pandolfi, M., Papayannis, A., Pappalardo, G., Pelon, J., Perrone, M. R., Pietruczuk, A., Pisani, G., Potma, C., Preissler, J., Pujadas, M., Putaud, J., Radu, C., Ravetta, F., Reigert, A., Rizi, V., Rocadenbosch, F., Rodriguez, A., Sauvage, L., Schmidt, J., Schnell, F., Schwarz, A., Seifert, P., Serikov, I., Sicard, M., Silva, A. M., Simeonov, V., Siomos, N., Sirch, T., Spinelli, N., Stoyanov, D., Talianu, C., Tesche, M., De Tomasi, F., Trickl, T., Vaughan, G., Volten, H., Wagner, F., Wandinger, U., Wang, X., Wiegner, M. and Wilson, K. M.: EARLINET climatology (2000-2010), World Data Centre for Climate, doi:http://dx.doi.org/10.1594/WDCC/EN_Climatology _2000-2010, 2014b.

The EARLINET publishing group 2000-2010, Adam, M., Alados-Arboledas, L., Althausen, D., Amiridis, V., Amodeo, A., Ansmann, A., Apituley, A., Arshinov, Y., Balis, D., Belegante, L., Bobrovnikov, S., Boselli, A., Bravo-Aranda, J. A., Bosenberg, J., Carstea, E., Chaikovsky, A., Comeron, A., D’Amico, G., Daou, D., Dreischuh, T., Engelmann, R., Finger, F., Freudenthaler, V., Garcia-Vizcaino, D., Garcia, A. J. F., Geiss, A., Giannakaki, E., Giehl, H., Giunta, A., De Graaf, M., Granados-Munoz, M. J., Grein, M., Grigorov, I., Gross, S., Gruening, C., Guerrero-Rascado, J. L., Haeffelin, M., Hayek, T., Iarlori, M., Kanitz, T., Kokkalis, P., Linne, H., Madonna, F., Mamouriat, R.-E., Matthias, V., Mattis, I., Menendez, F. M., Mitev, V., Mona, L., Morille, Y., Munoz, C., Muller, A., Muller, D., NavasGuzman, F., Nemuc, A., Nicolae, D., Pandolfi, M., Papayannis, A., Pappalardo, G., Pelon, J., Perrone, M. R., Pietruczuk, A., Pisani, G., Potma, C., Preissler, J., Pujadas, M., Putaud, J., Radu, C., Ravetta, F., Reigert, A., Rizi, V., Rocadenbosch, F., Rodriguez, A., Sauvage, L., Schmidt, J., Schnell, F., Schwarz, A., Seifert, P., Serikov, I., Sicard, M., Silva, A. M., Simeonov, V., Siomos, N., Sirch, T., Spinelli,

N., Stoyanov, D., Talianu, C., Tesche, M., De Tomasi, F., Trickl, T., Vaughan, G., Volten, H., Wagner, F., Wandinger, U., Wang, X., Wiegner, M. and Wilson, K. M.: EARLINET observations related to Saharan Dust events (2000-2010), World Data Centre for Climate, doi:http://dx.doi.org/10.1594/WDCC/EARLINET_SaharanDust_2000-2010,2014d. 
Atmos. Meas. Tech. Discuss., doi:10.5194/amt-2015-337, 2016

Manuscript under review for journal Atmos. Meas. Tech.

Published: 2 February 2016

(c) Author(s) 2016. CC-BY 3.0 License.

\author{
Atmospheric \\ Measurement \\ Techniques \\ Discussions
}

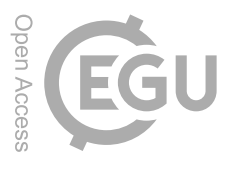

The EARLINET publishing group 2000-2010, Adam, M., Alados-Arboledas, L., Althausen, D., Amiridis, V., Amodeo, A., Ansmann,

A., Apituley, A., Arshinov, Y., Balis, D., Belegante, L., Bobrovnikov, S., Boselli, A., Bravo-Aranda, J. A., Bosenberg, J., Carstea, E., Chaikovsky, A., Comeron, A., D’Amico, G., Daou, D., Dreischuh, T., Engelmann, R., Finger, F., Freudenthaler, V., Garcia-Vizcaino, D., Garcia, A. J. F., Geiss, A., Giannakaki, E., Giehl, H., Giunta, A., De Graaf, M., Granados-Munoz, M. J., Grein, M., Grigorov, I.,

Gross, S., Gruening, C., Guerrero-Rascado, J. L., Haeffelin, M., Hayek, T., Iarlori, M., Kanitz, T., Kokkalis, P., Linne, H., Madonna, F., Mamouriat, R.-E., Matthias, V., Mattis, I., Menendez, F. M., Mitev, V., Mona, L., Morille, Y., Munoz, C., Muller, A., Muller, D., NavasGuzman, F., Nemuc, A., Nicolae, D., Pandolfi, M., Papayannis, A., Pappalardo, G., Pelon, J., Perrone, M. R., Pietruczuk, A., Pisani, G., Potma, C., Preissler, J., Pujadas, M., Putaud, J., Radu, C., Ravetta, F., Reigert, A., Rizi, V., Rocadenbosch, F., Rodriguez, A., Sauvage, L., Schmidt, J., Schnell, F., Schwarz, A., Seifert, P., Serikov, I., Sicard, M., Silva, A. M., Simeonov, V., Siomos, N., Sirch, T., Spinelli, N., Stoyanov, D., Talianu, C., Tesche, M., De Tomasi, F., Trickl, T., Vaughan, G., Volten, H., Wagner, F., Wandinger, U., Wang, X., Wiegner, M. and Wilson, K. M.: EARLINET observations related to volcanic eruptions (2000-2010), World Data Centre for Climate, doi:http://dx.doi.org/10.1594/WDCC/EN_VolcanicEruption_2000-2010,2014e.

Althausen, R. E. :PollyNET: a network of multiwavelength polarization Raman lidars. Proc SPIE 2013. doi:10.1117/12.2028921, 2013

Alvarez, J. M., Vaughan, M. A., Hostetler, C. A., Hunt, W. H., and Winker, D. M.: Calibration technique for polarization-sensitive lidars. J.

Atmos Oceanic Technol., 23, 683-699, 2006

Ansmann, A., Bosenberg, J., Chaikovsky, A., Comeron, A., Eckhardt, S., Eixmann, R., Freudenthaler,V., Ginoux, P., Komguem, L., Linne, H., Lopez, M. A., Matthias, V., Mattis, I., Mitev, V., Muller, D., Music, S., Nickovic, S., Pelon, J., Sauvage, L., Sobolewsky, P., Srivastava, M. K.,Stohl, A., Torres, O., Vaughn, G., Wandinger, U., and Wiegner, M.: Long-range transport of Saharan dust to Northern Europe: the 11-16 October 2001 outbreak observed with EARLINET. J. Geophys. Res., 108, 4783, doi:10.1029/2003JD003757, 2003

Ansmann, A., Seifert, P., Tesche, M., Wandinger, U., Baars, H., Tesche, M., Muller, D., Althausen, D., Engelmann, R., Pauliquevis, T. and Artaxo P.: Dust and smoke transport from Africa to South America: Lidar profiling over Cape Verde and the Amazon rainforest, Geophys. Res. Lett., 36, L11802, doi:10.1029/2009GL037923, 2009

Behrendt, A., and Nakamura, T.: Calculation of the calibration constant of polarization lidar and its dependency on atmospheric temperature, Optics Express, 10, 805-817, 2002

Biele, J., Beyerle, G., and Baumgarten, G.: Polarization Lidar: Correction of instrumental effects, Optics Express 7 , 427-435, 2000.

Bravo-Aranda, J.A, Belegante L., Freudenthaler V., Alados-Arboledas A., Nicolae D., Granados-Munoz M. J., Guerrero-Rascado, J. L., Amodeo A., D’Amico G., Engelmann R., Pappalardo G., Kokkalis P., Mamouri R., Papayannis A., Navas Guzman F., Olmo, F. J., Wandinger U. and Haeffelin, M.: Theoretical assessment of the lidar polarizing sensitivity, Atmos. Meas. Tech., (submitted), 2015.

Burton, S. P., Ferrare, R. A., Hostetler, C. A., Hair, J. W., Rogers, R. R., Obland, M. D., Butler, C., F., Cook, A., L., Harper, D., B., and

Froyd, K., D.: Aerosol classification using airborne High Spectral Resolution Lidar measurements - methodology and examples, Atmos. Meas. Tech., 5, 73-98, 2012

Chipman, R. A., Polarimetry, in: Handbook of Optics, Volume I (3rd Edition), Chapter 15. : McGraw-Hill, 2009.

Chipman, R. A., Mueller matrices, in: Handbook of Optics, Volume I (3rd Edition), Chapter 14. : McGraw-Hill, 2009.

Draxler, R.R. and Rolph, G.D., 2014. HYSPLIT (HYbrid Single-Particle Lagrangian Integrated Trajectory) Model access via NOAA ARL READY Website (http://ready.arl.noaa.gov/HYSPLIT.php). NOAA Air Resources Laboratory, Silver Spring, MD.

Fernald, F. G., Herman, B. M., and Reagan, J. A.: Determination of Aerosol height distributions by Lidar, J. Appl. Meteorol., 11, 482- 489, 1972. 
Atmos. Meas. Tech. Discuss., doi:10.5194/amt-2015-337, 2016

Manuscript under review for journal Atmos. Meas. Tech.

Published: 2 February 2016

(c) Author(s) 2016. CC-BY 3.0 License.

(c) (i)

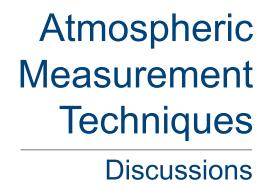

$\begin{array}{r}\text { Atmospheric } \\ \text { Measurement } \\ \text { Techniques } \\ \hline \text { Discussions }\end{array}$

Freudenthaler, V., Esselborn, M., Wiegner, M., Heese, B., Tesche, M., Ansmann, A., Muller, D., Althausen, D., Wirth, M., Andreas, F. I. X., Ehret, G., Knippertz, P., Toledano, C., Gasteiger, J., Garhammer, M., and Seefeldner, M.: Depolarization ratio profiling at several wavelengths in pure saharan dust during SAMUM 2006, Tellus B, 61(1), 165-179, 2009.

Freudenthaler, V.: Advanced calibration of linear depolarisation lidars, AMT EARLINET special issue, 2015.

5 Gasteiger, J. and Freudenthaler, V.: Benefit of depolarization ratio at $\lambda=1064 \mathrm{~nm}$ for the retrieval of the aerosol microphysics from lidar measurements, Atmospheric Measurement Techniques, 7(11), 3773-3781, doi:10.5194/amt-7-3773-2014, 2014.

Gross, S., Freudenthaler, V., Schepanski, K., Toledano, C., Schäfler, A., Ansmann, A. and Weinzierl, B.: Optical properties of long-range transported Saharan dust over Barbados as measured by dual-wavelength depolarization Raman lidar measurements, Atmospheric Chemistry and Physics, 15(19), 11067-11080, doi:10.5194/acp-15-11067-2015, 2015.

Gross, S., Esselborn, M., Weinzierl, B., Wirth, M., Fix, A. and Petzold, A.: Aerosol classification by airborne high spectral resolution lidar observations, Atmos. Chem. Phys., 13(5), 2487-2505, doi:10.5194/acp-13-2487-2013, 2013.

Gross, S., Tesche, M., Freudenthaler, V., Toledano, C., Wiegner, M., Ansmann, A., Althausen, D., and Seefeldner, M.: Characterization of Saharan dust, marine aerosols and mixtures of biomass-burning aerosols and dust by means of multi-wavelength depolarization and Raman lidar measurements during SAMUM 2, Tellus B 63, 706-724, 2011.

Guzman, F. N., Bravo-Aranda, J. A., Guerrero-Rascado, J. L., Granados-Munoz, M. J. and Arboledas, L. A.: Statistical analysis of aerosol optical properties retrieved by Raman lidar over Southeastern Spain, Tellus B, 65(21234), 2013.

Francisco Navas Guzmán, J. A. B.-A.: Statistical analysis of aerosol optical properties retrieved by Raman lidar over Southeastern Spain. Tellus B 65, 2013.

Hervo, M., Quennehen, B., Kristiansen, N. I., Boulon, J., Stohl, A., Fréville, P., Pichon, J.-M., Picard, D., Labazuy, P., Gouhier, M., Roger, J.C., Colomb, A., Schwarzenboeck, A., and Sellegri, K.: Physical and optical properties of 2010 Eyjafjallajökull volcanic eruption aerosol: ground-based, Lidar and airborne measurements in France., Atmos. Chem. Phys., 12, 1721-1736, doi:10.5194/acp-12-1721, 2012.

Hogan, R. J., Haywood, J. M., Westbrook, C. D., Dacre, H. F., Marenco, F., O’Connor, E. J., Johnson, B. T., Wrench, C. L., and Belcher, S. E.: Combined lidar and sun photometer retrievals of ash particle size and mass concentration from the Eyjafjallajökull volcano, J. Geophys. Res., in press, 2012.

Klett, J. D.: Lidar inversion with variable backscatter/extinction ratios, Applied Optics, 24(11), 1638, doi:10.1364/AO.24.001638, 1985.

Klett, J. D.: Stable Analytical Inversion Solution For Processing Lidar Returns, Appl. Opt., 20, 211-220, 1981.

Kokkalis, P., Papayannis, A., Amiridis, V., Mamouri, R. E., Veselovskii, I., Kolgotin, A., Tsaknakis, G., Kristiansen, N. I., Stohl, A. and Mona, L.: Optical, microphysical, mass and geometrical properties of aged volcanic particles observed over Athens, Greece, during the Eyjafjallajökull eruption in April 2010 through synergy of Raman lidar and sunphotometer measurements, Atmos. Chem. Phys., 13(18), 9303-9320, doi:10.5194/acp-13-9303-2013, 2013.

Kovalev, V., and Eichinger, V.: Elastic lidar: Theory, Practice and Analysis Methods, Wiley Interscience Publ. New York, USA, 2004 Lu, S.-Y. and Chipman, R. A.: Interpretation of Mueller matrices based on polar decomposition, J. Opt. Soc. Am. A 13 , $1106-1113$, 1996. Madonna, F., Amodeo, A., Boselli, A., Cornacchia, C., Cuomo, V., D’Amico, G., Giunta, A., Mona, L. and Pappalardo, G.: CIAO: the CNR-IMAA advanced observatory for atmospheric research, Atmos. Meas. Tech., 4(6), 1191-1208, 2011.

Mamouri, R. E., Papayannis, A., Amiridis, V., Müller, D., Kokkalis, P., Rapsomanikis, S., Karageorgos, E. T., Tsaknakis, G., Nenes, A., Kazadzis, S. and Remoundaki, E.: Multi-wavelength Raman lidar, sun photometric and aircraft measurements in combination with inversion models for the estimation of the aerosol optical and physico-chemical properties over Athens, Greece, Atmos. Meas. Tech., 5(7), 1793-1808, doi:10.5194/amt-5-1793-2012, 2012. 
Atmos. Meas. Tech. Discuss., doi:10.5194/amt-2015-337, 2016

Manuscript under review for journal Atmos. Meas. Tech.

Published: 2 February 2016

(c) Author(s) 2016. CC-BY 3.0 License.
Atmospheric

Measurement

Techniques

Discussions

Mattis, I., Tesche, M., Grein, M., Freudenthaler, V., and Muller, D.: "Systematic error of lidar profiles caused by a polarization-dependent receiver transmission: quantification and error correction scheme", Appl. Optics. 48 , 2742-2751, 2009.

Measures R.M., 1992, Laser Remote Sensing. Fundamentals and Applications, Krieger Publishing Company, Malabar, Florida, USA.

Mona L., Liu Z., Muller D., Lidar Measurements for Desert Dust Characterization: An Overview, Advances in Meteorology, 2012, ID356265, doi:10.1155/2012/356265, 2012

Muller, D., Mattis, I., Wandinger, U., Ansmann, A., Althausen, D., Dubovik, O., Eckhardt, S., and Stohl, A., Saharan dust over a central European EARLINET-AERONET site: Combined observations with Raman lidar and Sun photometer. J. Geophys. Res., 108, 4345, doi:10.1029/2002JD002918, 2003

Nemuc, A., Vasilescu, J., Talianu, C., Belegante, L. and Nicolae, D.: Assessment of aerosol's mass concentrations from measured linear particle depolarization ratio (vertically resolved) and simulations. Atmos. Meas. Tech. 6, 3243-3255, 2013.

Nicolae, D., Nemuc A., Muller D., Talianu C., Vasilescu J., Belegante L. and Kolgotin A.: Characterization of fresh and aged biomass burning events using multiwavelength Raman lidar and mass spectrometry, J. Geophys. Res. Atmos., 118, doi:10.1002/jgrd.50324, 2013

R. Ossikovski.: Alternative depolarization criteria for Mueller matrices, J. Opt. Soc. Am. A 27 , 808-814, 2010.

Papayannis, A., Amiridis, V., Mona, L., Tsaknakis, G., Balis, D., Bosenberg, J., Tchaikovsky, A., De Tomasi, F., Grigorov, I., Mattis, I., Mitev, V., Muller D., Nickovic. S., Perez. C., Pietruczuk. A., Pisani. G., Ravetta. F., Rizi. V., Sicard. M., Trickl, T., Wiegner, M., Gerding, M., Mamouri, R. E., D'Amico, G. and Pappalardo, G.: Systematic lidar observations of Saharan dust over Europe in the frame of EARLINET (2000-2002)”, J. Geophys. Res., doi:10.1029/2007JD009028, 2008.

Pappalardo, G., Amodeo, A., Apituley, A., Comeron, A., Freudenthaler, V., Linné, H., Ansmann, A., Bösenberg, J., D’Amico, G., Mattis, I., Mona, L., Wandinger, U., Amiridis, V., Alados-Arboledas, L., Nicolae, D. and Wiegner, M.: EARLINET: towards an advanced sustainable European aerosol lidar network, Atmos. Meas. Tech. Discuss., 7(3), 2929-2980, doi:10.5194/amtd-7-2929-2014, 2014.

Pappalardo, G., Mona, L., D’Amico, G., Wandinger, U., Adam, M., Amodeo, A., Ansmann, A., Apituley, A., Alados Arboledas, L., Balis, D., Boselli, A., Bravo-Aranda, J. A., Chaikovsky, A., Comeron, A., Cuesta, J., De Tomasi, F., Freudenthaler, V., Gausa, M., Giannakaki, E., Giehl, H., Giunta, A., Grigorov, I., Groß, S., Haeffelin, M., Hiebsch, A., Iarlori, M., Lange, D., Linné, H., Madonna, F., Mattis, I., Mamouri, R.-E., McAuliffe, M. A. P., Mitev, V., Molero, F., Navas-Guzman, F., Nicolae, D., Papayannis, A., Perrone, M. R., Pietras, C., Pietruczuk, Pisani, G., Preißler, J., Pujadas, M., Rizi, V., Ruth, A. A., Schmidt, J., Schnell, F., Seifert, P., Serikov, I., Sicard, M., Simeonov, V., Spinelli, N., Stebel, K., Tesche, M., Trickl, T., Wang, X., Wagner, F., Wiegner, M., and Wilson, K. M.: Four-dimensional distribution of the 2010 Eyjafjallajökull volcanic cloud over Europe observed by EARLINET, Atmos. Chem. Phys. Discuss., 12, 3020330257, doi:10.5194/acpd-12-30203-2012, 2012

Petzold., A , M. E. ICAROHS - Inter-Comparison of Aerosol Retrievals and Observational Requirements for Multi-wavelength HSRL Systems, 2010.

Rolph, G.D., 2014. Real-time Environmental Applications and Display sYstem (READY) Website (http://ready.arl.noaa.gov). NOAA Air Resources Laboratory, Silver Spring, MD.

Sassen, K. Polarization in Lidar, Lidar, C. Weitkamp (Eds.), Springer Press: New York, pp. 19-42, 2005

Sassen, K., Zhu, J., Webley, P., Dean, K., and Cobb, P., Volcanic ash plume identification using polarization lidar: Augustine eruption, Alaska. Geophys. Res. Lett., 34, L08803, doi:10.1029/2006GL027237, 2007

Snels, M.,. Cairo, F, Colao, F., and Di Donfrancesco, G.: Calibration method for depolarization lidar measurements, Int. J. Remote Sens. 30 , 5725-5736, 2009. 
Atmos. Meas. Tech. Discuss., doi:10.5194/amt-2015-337, 2016

Manuscript under review for journal Atmos. Meas. Tech.

Published: 2 February 2016

(c) Author(s) 2016. CC-BY 3.0 License.

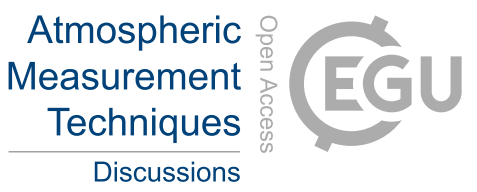

(c) (1)

Tesche, M., Gross, S., Ansmann, A., Muller, D., Althausen, D., Freudenthaler, V., and Esselborn, M., Profiling of Saharan dust and biomassburning smoke with multiwavelength polarization Raman lidar at Cape Verde, Tellus B 63 , 649-676, 2011. 
Atmos. Meas. Tech. Discuss., doi:10.5194/amt-2015-337, 2016

Manuscript under review for journal Atmos. Meas. Tech.

Published: 2 February 2016

(c) Author(s) 2016. CC-BY 3.0 License.

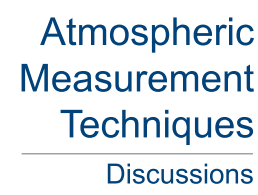

(c) (i)

Table 1. Calibration values for EARLINET lidar systems performing depolarization calibration measurements

\begin{tabular}{lllllll}
\hline Site & $\eta_{\text {rot }}$ & $\Delta \eta_{\text {rot }}$ & $\eta_{\text {pol }}$ & $\Delta \eta_{\text {pol }}$ & $\mathrm{D}_{O}$ & $\operatorname{err} \Delta \mathrm{D}_{O}$ \\
\hline Granada & 0.14 & \pm 0.03 & 0.24 & \pm 0.03 & 0.35 & \pm 0.04 \\
Bucharest & 1.15 & \pm 0.08 & 1.9 & \pm 0.1 & 0.227 & \pm 0.1 \\
Potenza & 22.67 & \pm 0.10 & 25.3 & \pm 0.10 & 0.055 & \pm 0.01 \\
Athens & 0.054 & \pm 0.01 & - & - & - & - \\
Leipzig & - & - & 0.089 & \pm 0.01 & - & - \\
Munich & 42.2 & \pm 0.4 & 47.5 & \pm 0.9 & 0.059 & \pm 0.015 \\
\hline
\end{tabular}

Table 2. Volume linear depolarization values of calibrated and non-calibrated retrievals for the RALI lidar system on $26^{\text {th }}$ of September 2013.

\begin{tabular}{lllll}
\hline & $\begin{array}{l}\text { Not-calibrated } \\
\text { prfiles }\end{array}$ & $\begin{array}{l}\eta_{\text {pol }}^{*} \text { corrected, } \\
\text { no } \alpha \text { correction }\end{array}$ & $\begin{array}{l}\eta_{\text {pol }}^{*} \text { corrected, } \\
\alpha \text { correction }\end{array}$ & $\begin{array}{l}\text { Difference: non } \\
\text { calibrated and/ } \\
\text { calibrated profiles } \\
\end{array}$ \\
& 0.27 & 0.42 & 0.40 & $+\alpha$ corrected $)$ \\
\hline cloud & 0.12 & 0.07 & $<0.01$ & -0.11 \\
\hline free troposphere & 0.12 & & +0.13 \\
\hline
\end{tabular}


Atmos. Meas. Tech. Discuss., doi:10.5194/amt-2015-337, 2016

Manuscript under review for journal Atmos. Meas. Tech.

Published: 2 February 2016

(c) Author(s) 2016. CC-BY 3.0 License.
Atmospheric Measurement Techniques

Discussions

(c) (1)

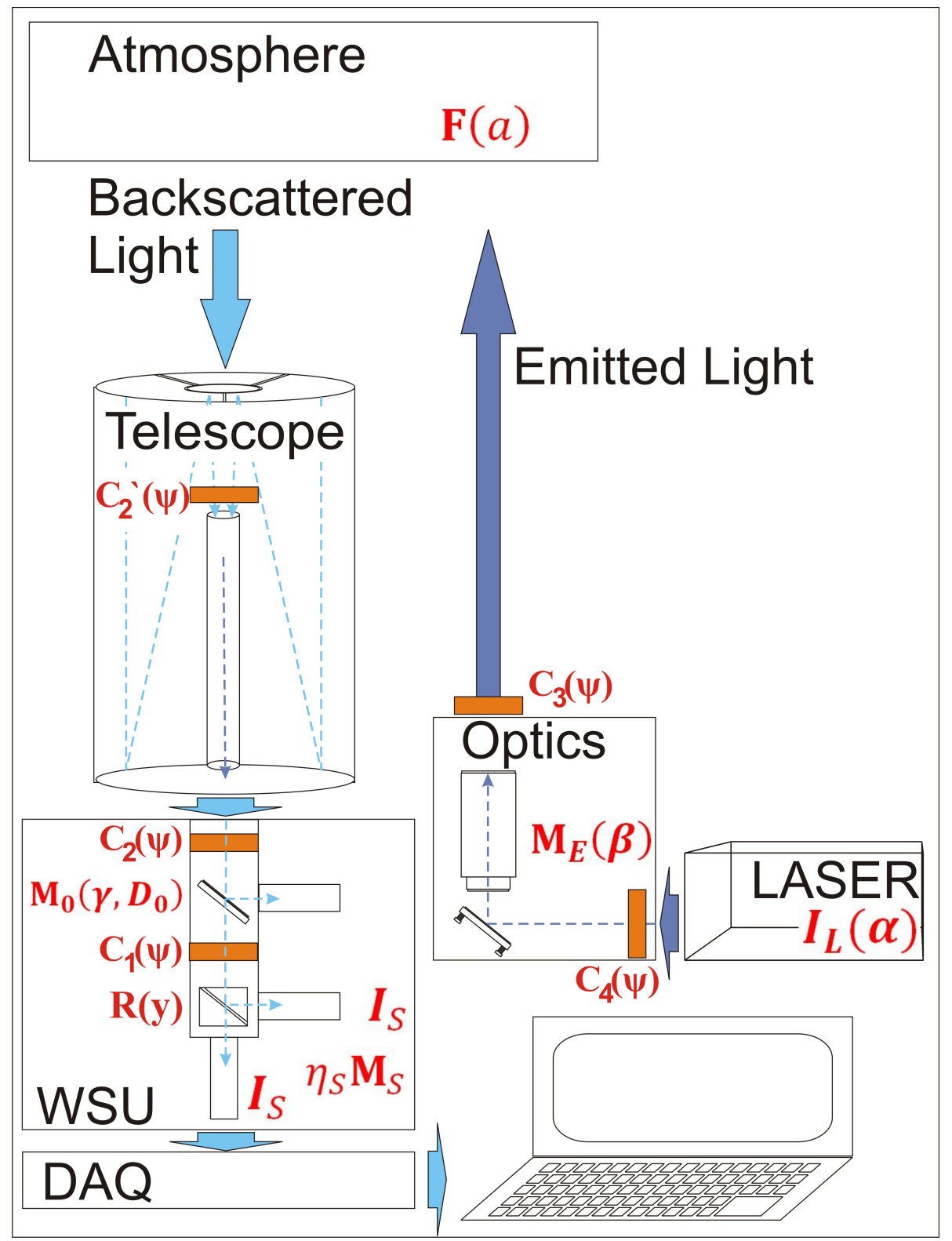

Figure 1. Schematics of a lidar system: emission block: laser and the emission optics; receiving block: telescope, wavelength separation unit (WSU) and data acquisition (DAQ) block. - Mueller-Stokes notations (red) for specific optical components used further in the study; Possible positions of the calibration units (orange) in respect to the optical layout; WSU: Wavelength Separation Unit; DAQ: Data Acquisition 
Atmos. Meas. Tech. Discuss., doi:10.5194/amt-2015-337, 2016

Manuscript under review for journal Atmos. Meas. Tech.

Published: 2 February 2016

(c) Author(s) 2016. CC-BY 3.0 License.
Atmospheric Measurement

Techniques

Discussions

(c) (1)
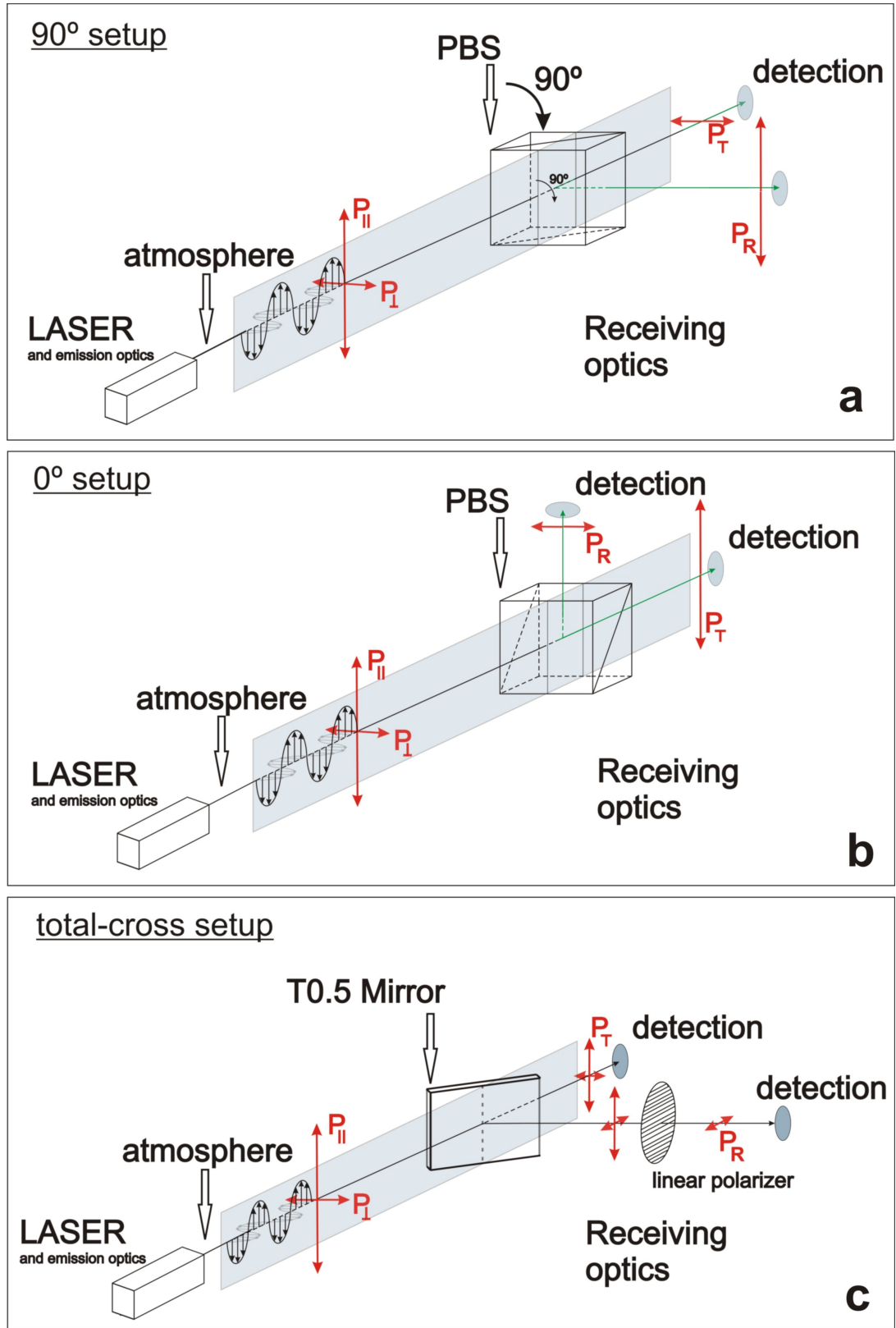

Figure 2. Detection setups (according with (Freudenthaler et al., 2009)). $P_{\perp}$ and $P_{\|}$- collected radiation (parallel and cross components). $P_{T}$ and $P_{R}$ - detected components of the collected radiation (with contribution from the receiving optics). a) $90^{\circ}$ detection setup; b) $0^{\circ}$ detection setup; c) detection setup for PollyXT type lidar systems. PBS - Polarizing Beam Splitter, T0.5 mirror - 0.5 transmittance reflecting mirror 
Atmos. Meas. Tech. Discuss., doi:10.5194/amt-2015-337, 2016

Manuscript under review for journal Atmos. Meas. Tech.

Published: 2 February 2016

(c) Author(s) 2016. CC-BY 3.0 License.
Atmospheric Measurement Techniques

Discussions

(c) (1)
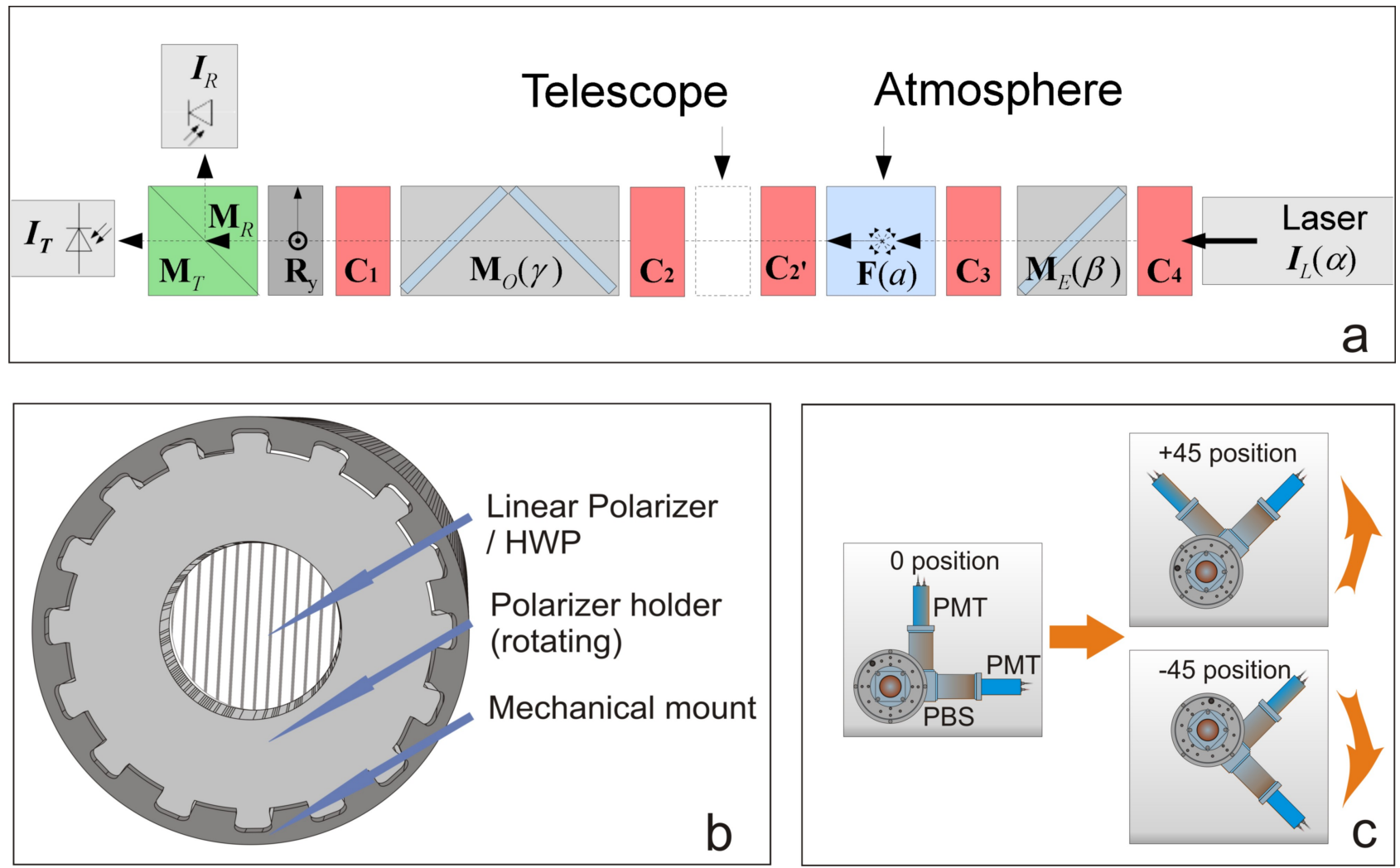

Figure 3. Calibration blocks: a) schematics of a polarization sensitive lidar system with Mueller matrix block elements, different calibrator positions (red blocks - C); b) multiangle mechanical rotator mount for the $\Delta 90^{\circ}$ polarizer calibrator or the $\Delta 90^{\circ}$ optical calibrator. $22.5^{\circ}$ rotation step. HWP - Half Wave Plate; c) mechanical rotator for the $\Delta 90^{\circ}$ mechanical calibrator. PMT - photomultiplier, PBS - Polarizing Beam Splitter 
Atmos. Meas. Tech. Discuss., doi:10.5194/amt-2015-337, 2016

Manuscript under review for journal Atmos. Meas. Tech.

Published: 2 February 2016

(c) Author(s) 2016. CC-BY 3.0 License.

(c) (i)
Atmospheric

Measurement

Techniques

Discussions
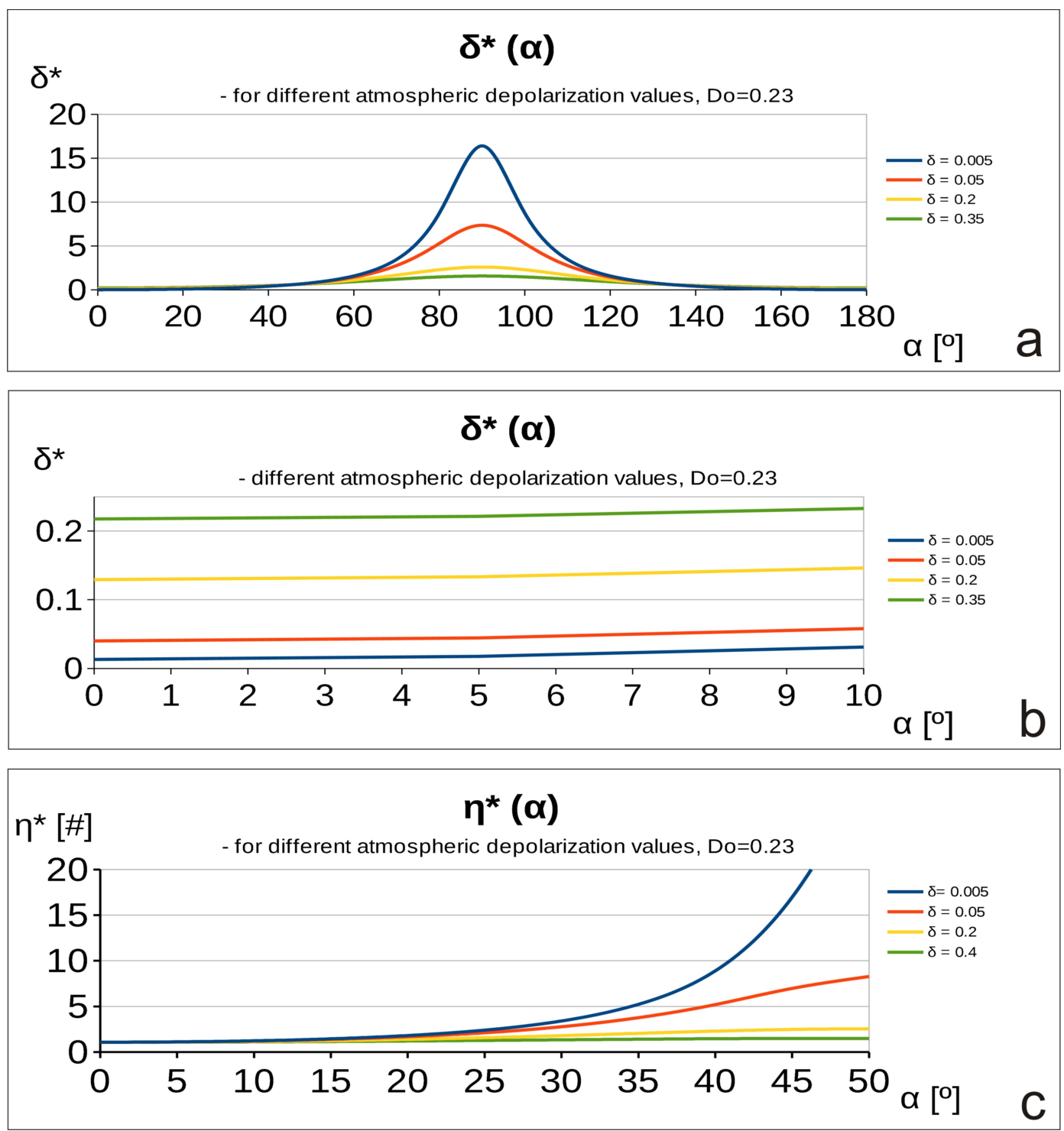

Figure 4. Numerical simulation: a) calibrated signal ratio - $\alpha$ simulations for different atmospheric depolarization values - $\alpha\left(0^{\circ}: 180^{\circ}\right)$; b) calibrated signal ratio - $\alpha$ simulations for different atmospheric depolarization values $-\alpha\left(-10^{\circ}: 10^{\circ}\right)$; c) $\eta-\alpha$ simulations for different atmospheric depolarization values 
Atmos. Meas. Tech. Discuss., doi:10.5194/amt-2015-337, 2016

Manuscript under review for journal Atmos. Meas. Tech.

Published: 2 February 2016

(c) Author(s) 2016. CC-BY 3.0 License.

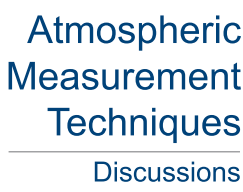

(c) (1)
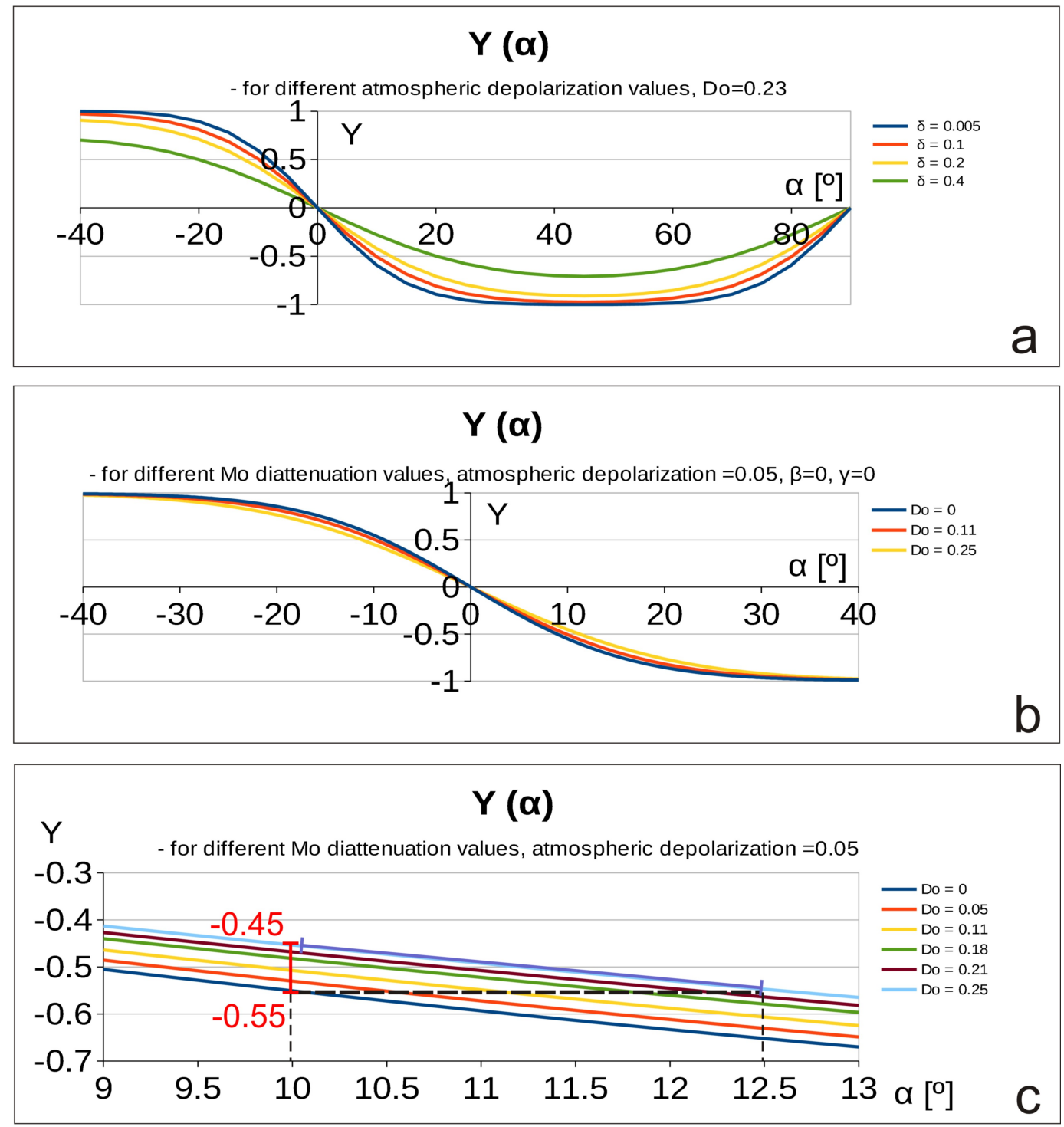

Figure 5. Numerical simulation: a) $\mathrm{Y}$ - $\alpha$ simulations - for several atmospheric depolarization values; b) Y - $\alpha$ simulations - for several effective diattenuation values; c) $\mathrm{Y}-\alpha$ simulations - for several effective diattenuation values - zoom in 
Atmos. Meas. Tech. Discuss., doi:10.5194/amt-2015-337, 2016

Manuscript under review for journal Atmos. Meas. Tech.

Published: 2 February 2016

(c) Author(s) 2016. CC-BY 3.0 License.
Atmospheric

Measurement

Techniques

Discussions

(c) (i)
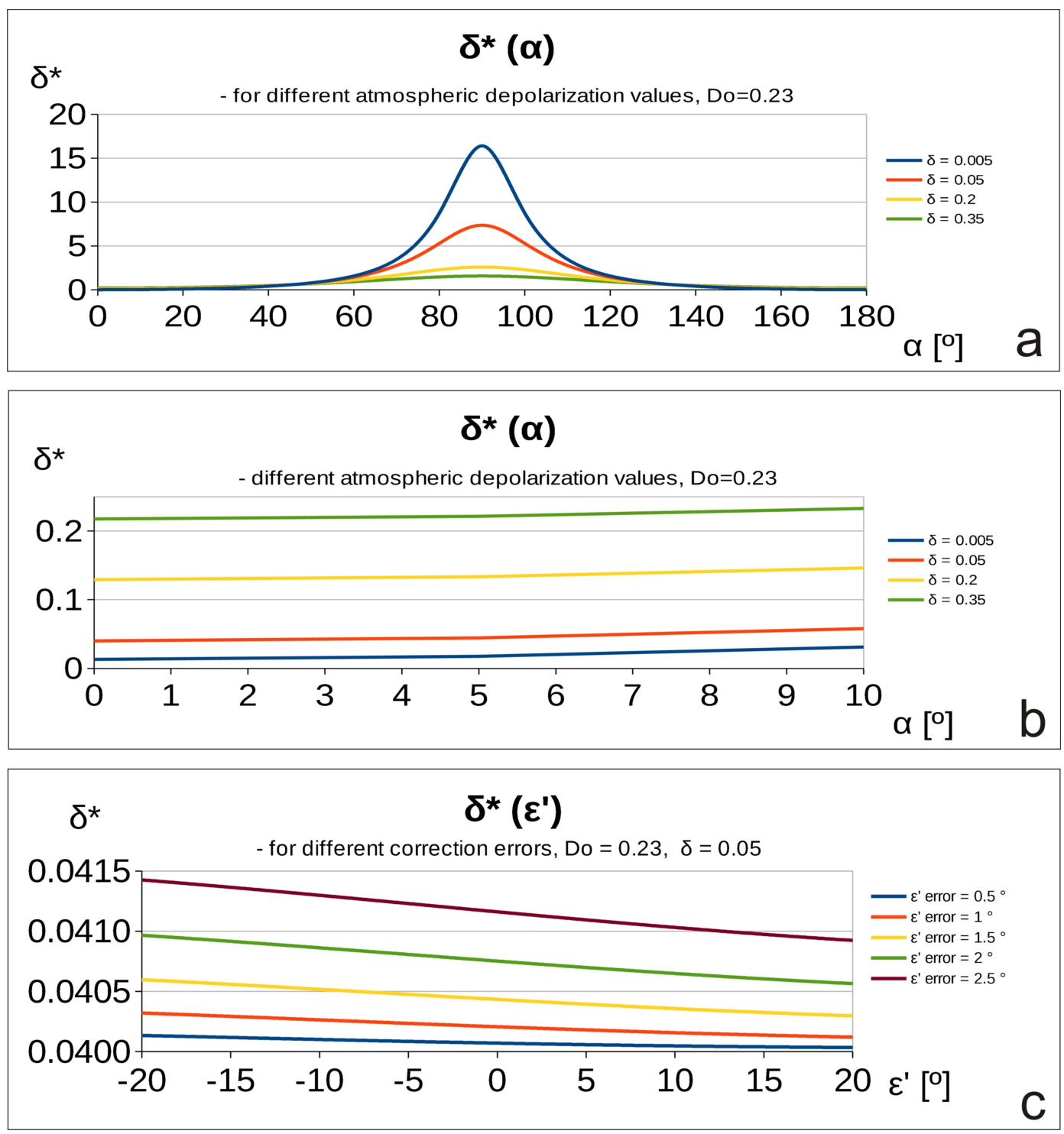

Figure 6. Numerical simulation: a) volume linear depolarization ratio - $\epsilon$ ' dependence when using the $\alpha$ correction module in front of the PBS; b) volume linear depolarization ratio - $\epsilon$ ' dependence when using the $\alpha$ correction module in front of the receiving optics; c) correction offset for different precision values when using the HWP rotator in front of the receiving optics 
Atmos. Meas. Tech. Discuss., doi:10.5194/amt-2015-337, 2016

Manuscript under review for journal Atmos. Meas. Tech.

Published: 2 February 2016

(c) Author(s) 2016. CC-BY 3.0 License.
Atmospheric

Measurement

Techniques

Discussions

(c) (i)
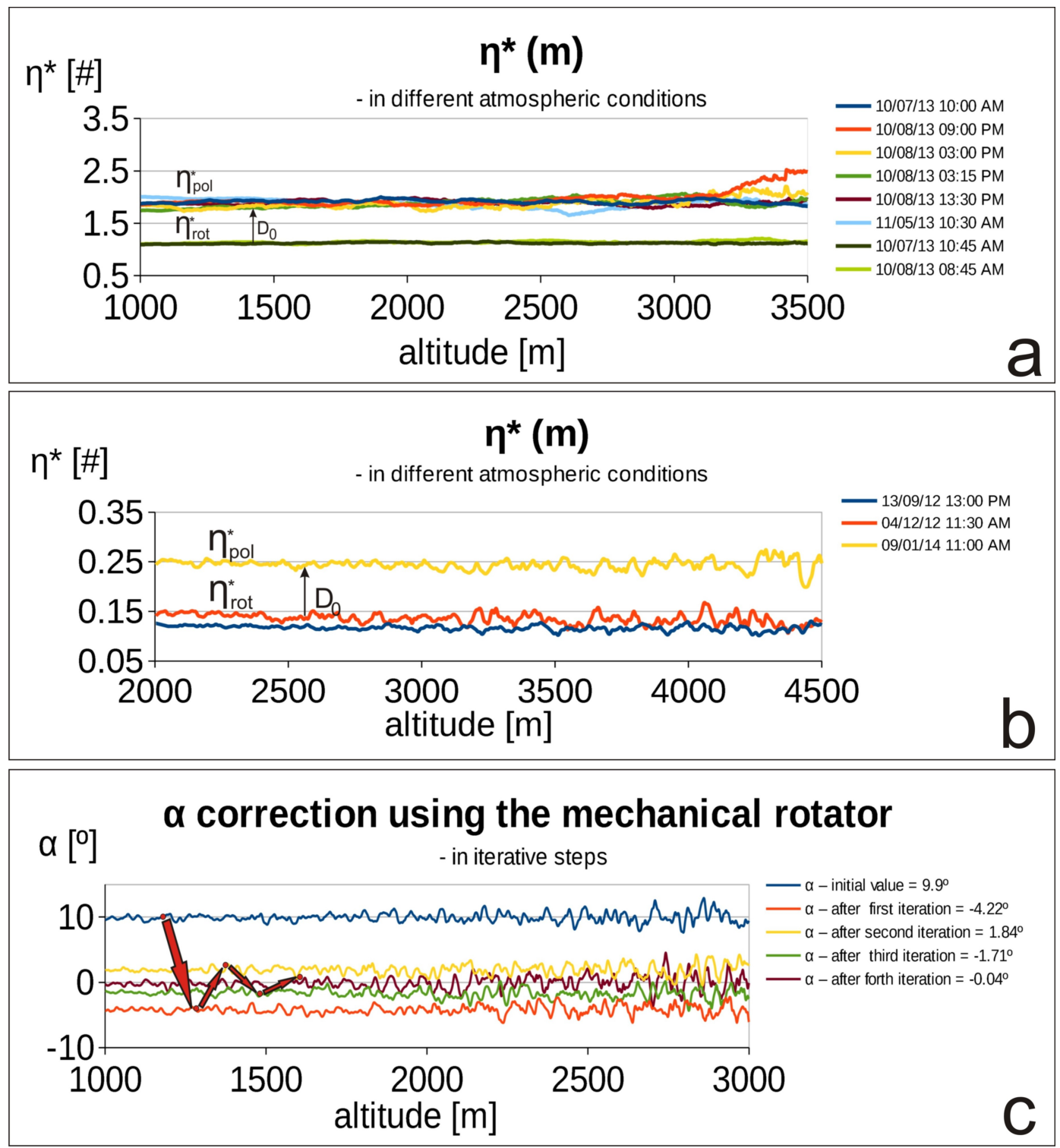

Figure 7. Calibration values using two experimental techniques: polarizer rotation calibrator: $\eta_{\text {pol }}^{*}$ and mechanical rotation calibrator: $\eta_{\text {rot }}^{*}$ a) for the Bucharest lidar; b) for the Granada lidar; c) assessment and correction of $\alpha(\mathrm{Y})$ parameter for the Bucharest lidar using the iterative procedure, mechanical rotator in front of the PBS 
Atmos. Meas. Tech. Discuss., doi:10.5194/amt-2015-337, 2016

Manuscript under review for journal Atmos. Meas. Tech.

Published: 2 February 2016

(c) Author(s) 2016. CC-BY 3.0 License.
Atmospheric Measurement Techniques

Discussions (c) (1)
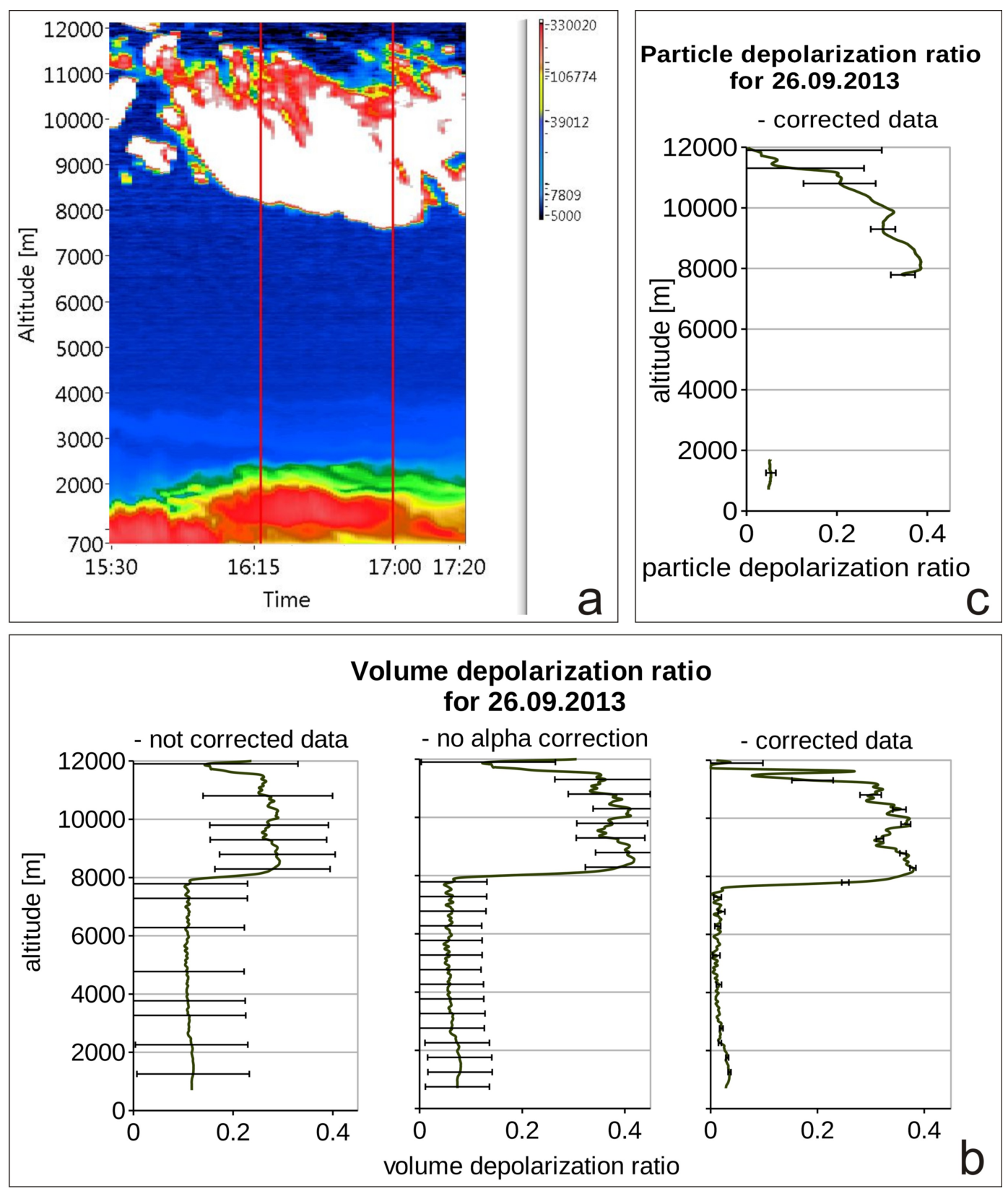

Figure 8. Data from $26^{\text {th }}$ of September 2013 at the RALI-Bucharest lidar system. a) range corrected time series at 532nm; b) volume linear depolarization ratios for not-corrected, $\eta_{\text {pol }}^{*}$ corrected and $\eta_{p o l}^{*}$ and $\alpha(\mathrm{Y})$ corrected profile at 532nm - smoothed data, one hour average; c) particle depolarization ratio profile at $532 \mathrm{~nm}$ - smoothed data, one hour average 
Atmos. Meas. Tech. Discuss., doi:10.5194/amt-2015-337, 2016

Manuscript under review for journal Atmos. Meas. Tech.

Published: 2 February 2016

(c) Author(s) 2016. CC-BY 3.0 License.
Atmospheric

Measurement

Techniques

Discussions

(c) (i)
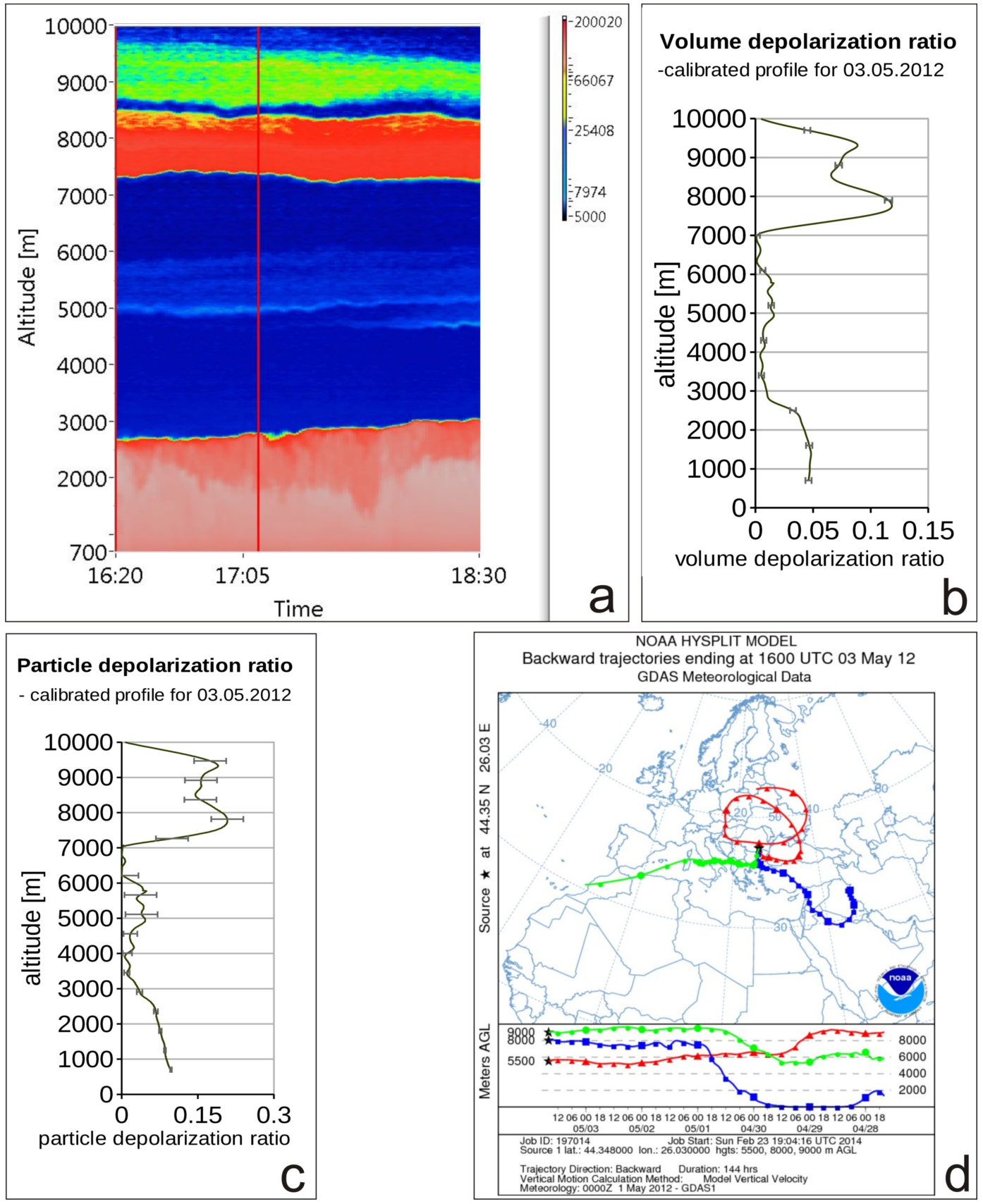

Figure 9. Data from $3^{r} d$ of May 2012, at the RALI-Bucharest lidar system a) range corrected time series at 532nm; b) volume linear depolarization ratio - corrected profile at 532nm - smoothed data, one hour average; c) particle linear depolarization ratio - corrected profile at 532nm - smoothed data, one hour average; d) HYSPLIT back-trajectories analysis (-144h) for the detected layers, at the Bucharest site 
Atmos. Meas. Tech. Discuss., doi:10.5194/amt-2015-337, 2016

Manuscript under review for journal Atmos. Meas. Tech.

Published: 2 February 2016

(c) Author(s) 2016. CC-BY 3.0 License.
Atmospheric

Measurement

Techniques

Discussions

(c) (1)

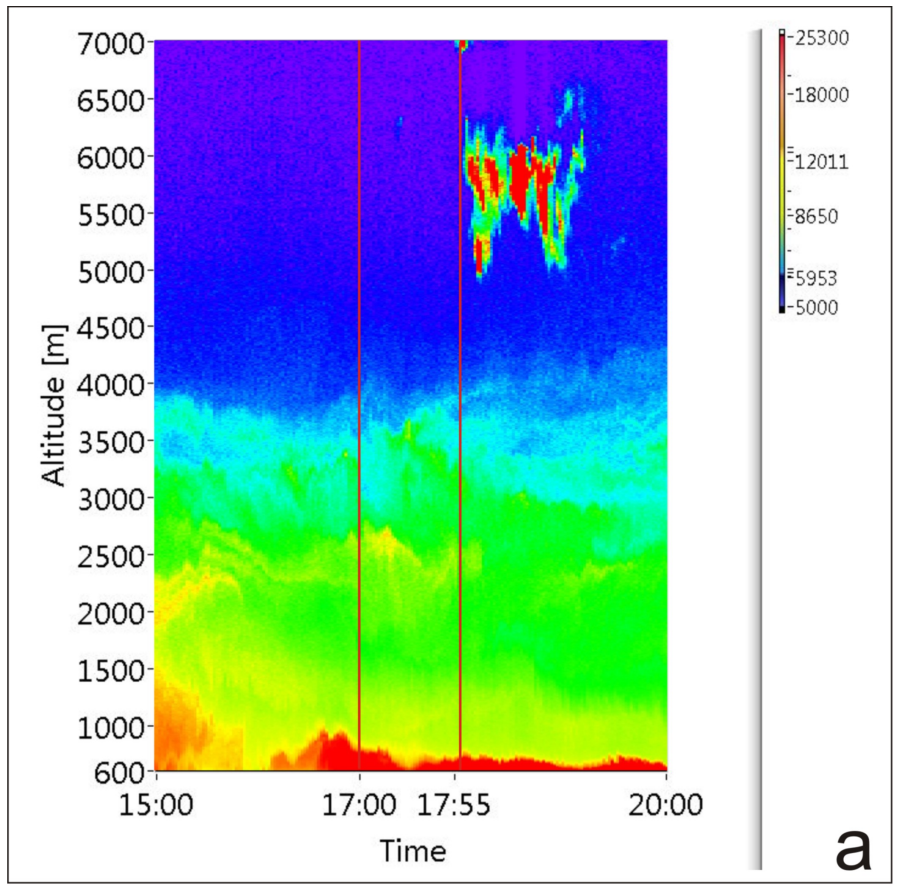

Volume depolarization ratio -calibrated profile for 03.05.2012

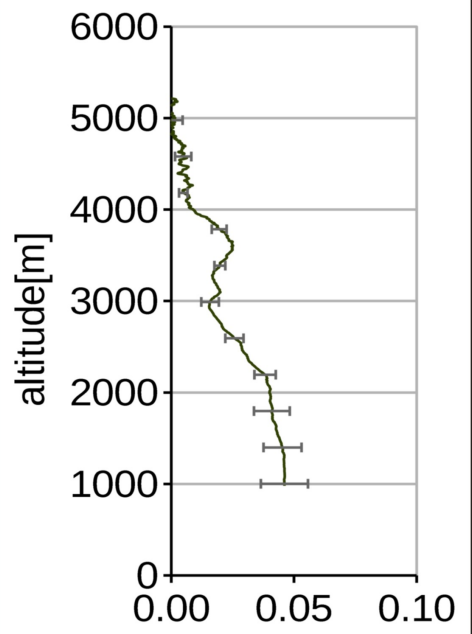

volume depolarization ratio
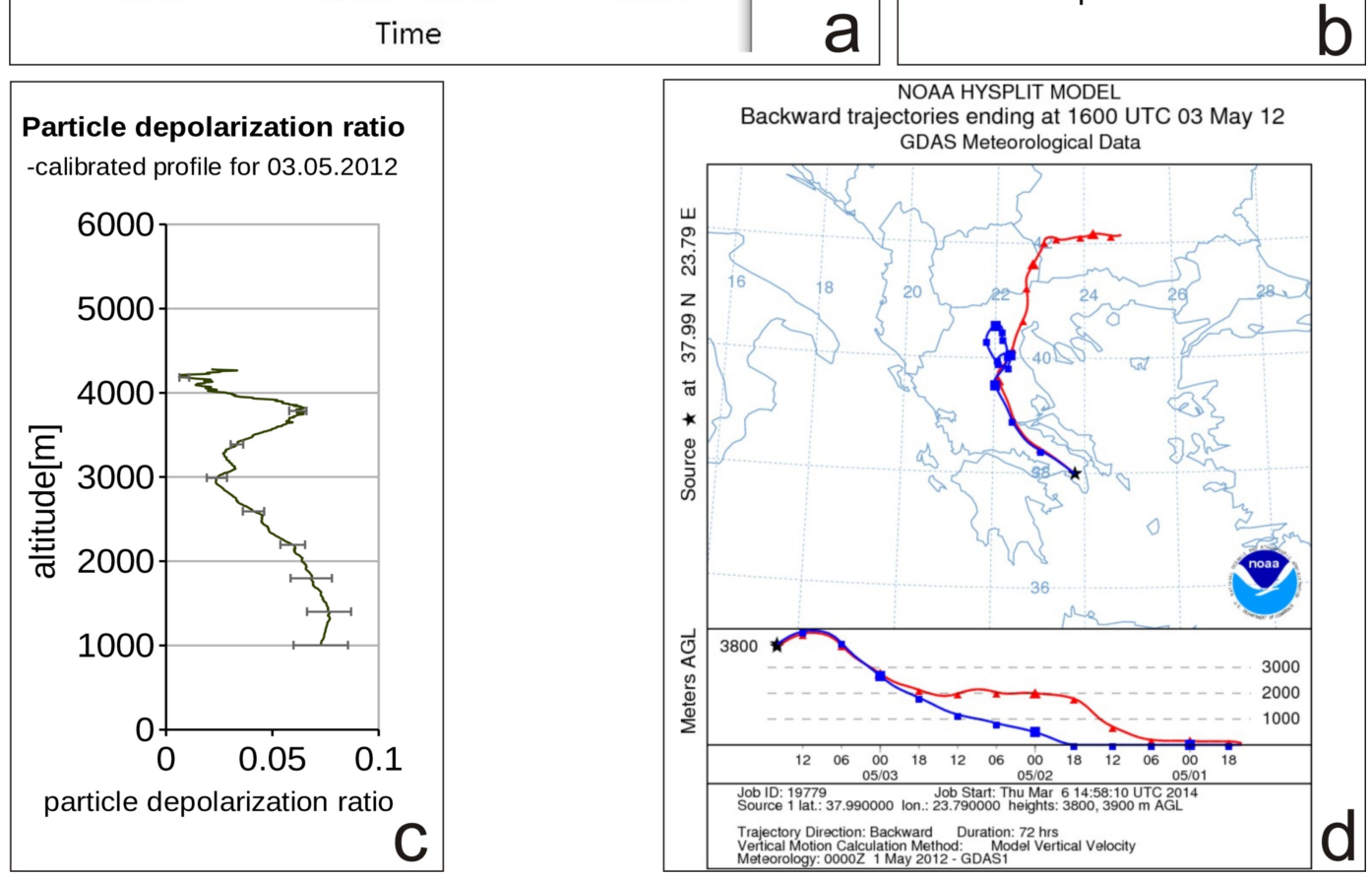

Figure 10. Data from $3^{r} d$ of May 2012, at the Athens lidar system a) range corrected time series at 532nm; b) volume linear depolarization ratio - corrected profile at 532nm - smoothed data, one hour average; c) particle linear depolarization ratio - corrected profile at 532nm smoothed data, one hour average; d) HYSPLIT back-trajectories analysis (-72h) for the detected layers, at the Athens site 
Atmos. Meas. Tech. Discuss., doi:10.5194/amt-2015-337, 2016

Manuscript under review for journal Atmos. Meas. Tech.

Published: 2 February 2016

(c) Author(s) 2016. CC-BY 3.0 License.
Atmospheric

Measurement

Techniques

Discussions

(c) (1)
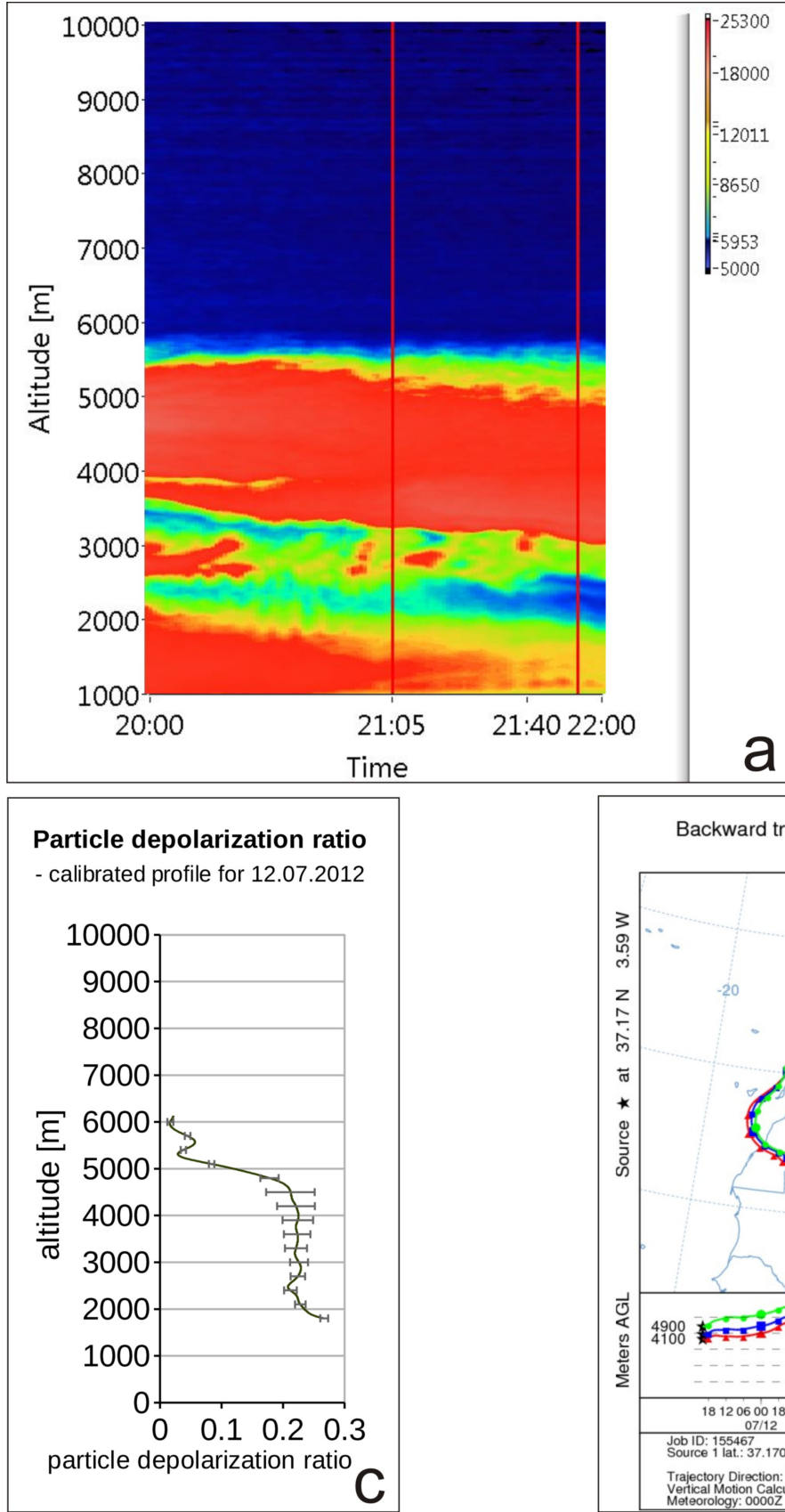

Volume depolarization ratio

-corrected profile for 12.07.2012

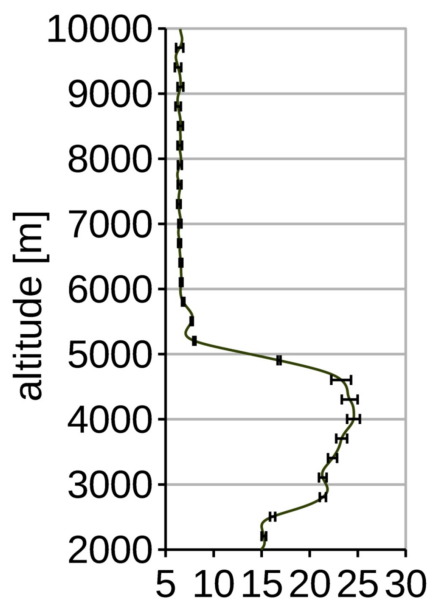

volume depolarization ratio a

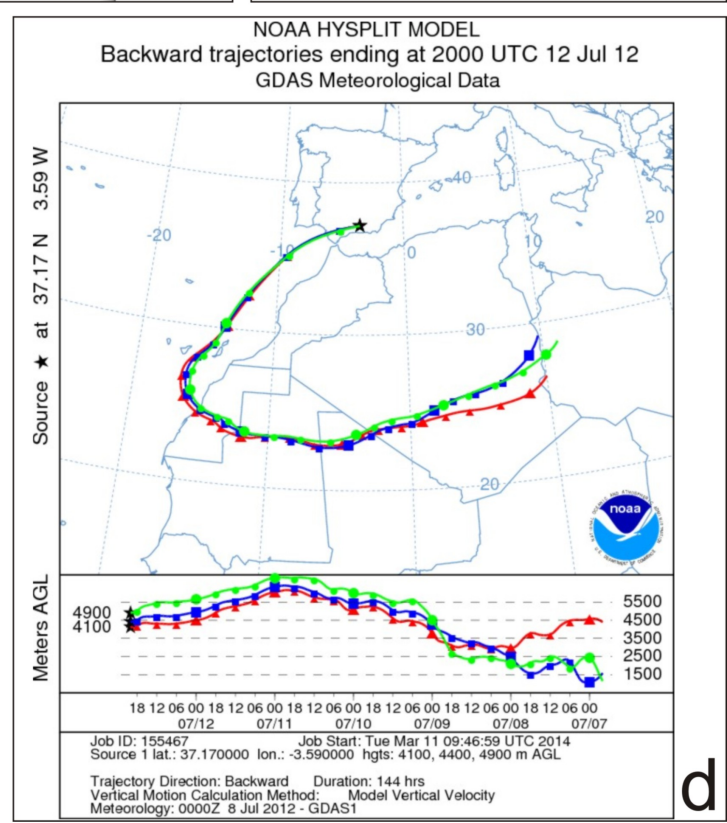

Figure 11. Data from 12 of July 2012, at the Mulhacen-Granada lidar system a) range corrected time series at 532nm; b) volume linear depolarization ratio - corrected profile at 532nm - smoothed data, one hour average; c) particle linear depolarization ratio - corrected profile at 532nm - smoothed data, one hour average; d) HYSPLIT back-trajectories analysis (-144h) for the detected layers, at the Granada site 
Atmos. Meas. Tech. Discuss., doi:10.5194/amt-2015-337, 2016

Manuscript under review for journal Atmos. Meas. Tech.

Published: 2 February 2016

(c) Author(s) 2016. CC-BY 3.0 License.
Atmospheric

Measurement

Techniques

Discussions

(c) (1)

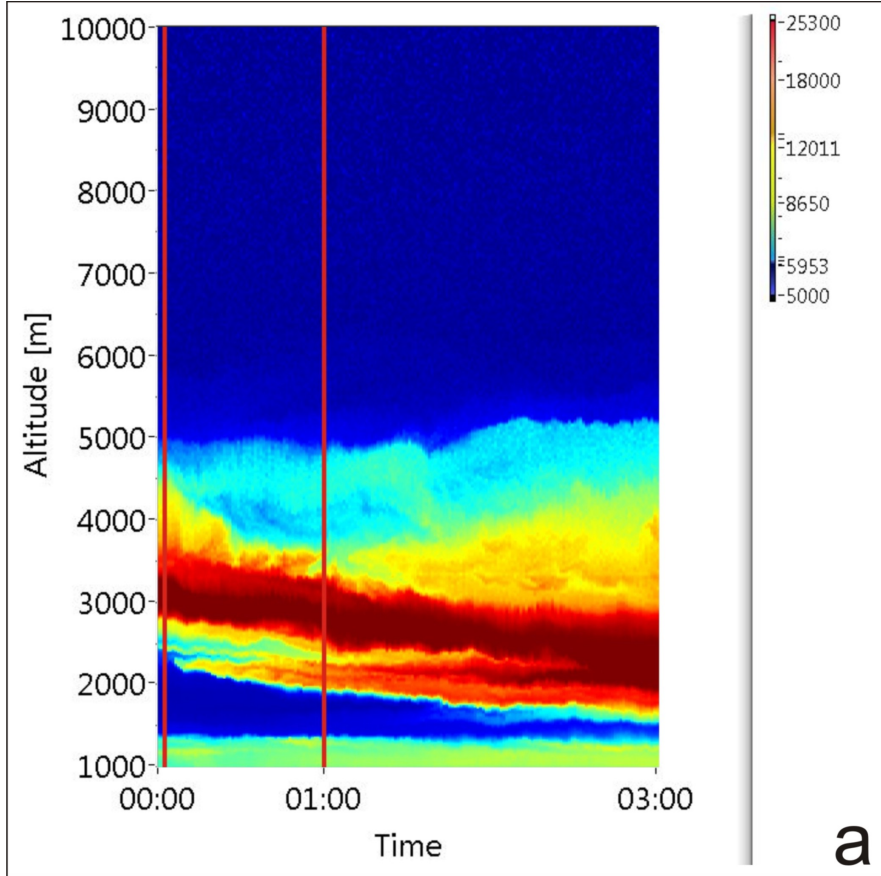

Volume depolarization ratio

- calibrated profile for 05.08 .2012

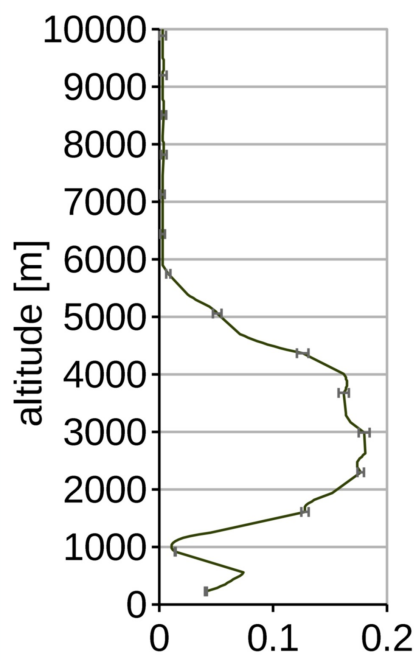

volume depolarization ratio
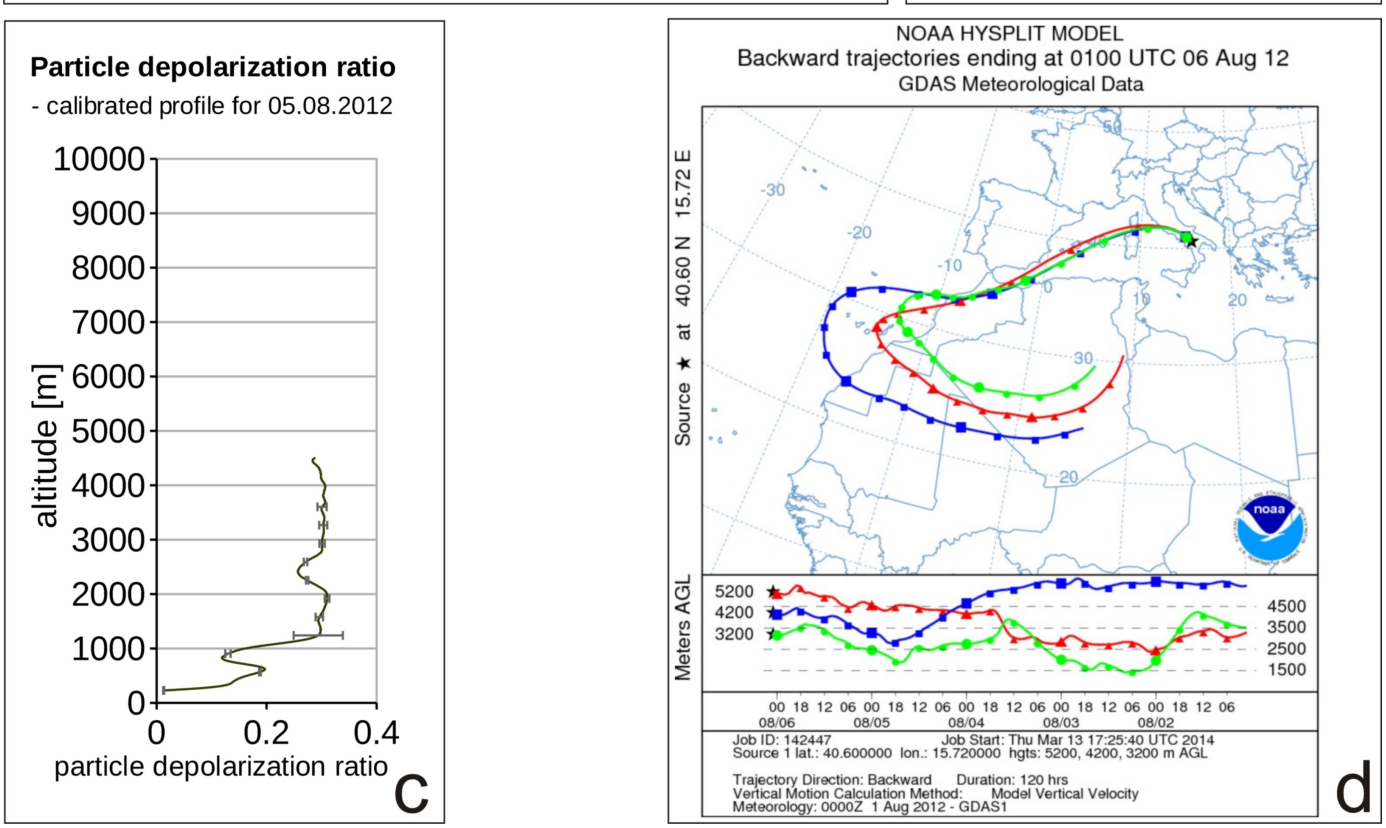

Figure 12. Data from $06^{\text {th }}$ of August 2012, at the MUSA-Potenza lidar system a) range corrected time series at 532nm; b) volume linear depolarization ratio - corrected profile at 532nm - smoothed data, one hour average; c) particle linear depolarization ratio - corrected profile at 532nm - smoothed data, one hour average; d) HYSPLIT back-trajectories analysis (-120h) for the detected layers, at the Potenza site 
Atmos. Meas. Tech. Discuss., doi:10.5194/amt-2015-337, 2016

Manuscript under review for journal Atmos. Meas. Tech.

Published: 2 February 2016

(c) Author(s) 2016. CC-BY 3.0 License.
Atmospheric

Measurement

Techniques

Discussions

(c) (1)

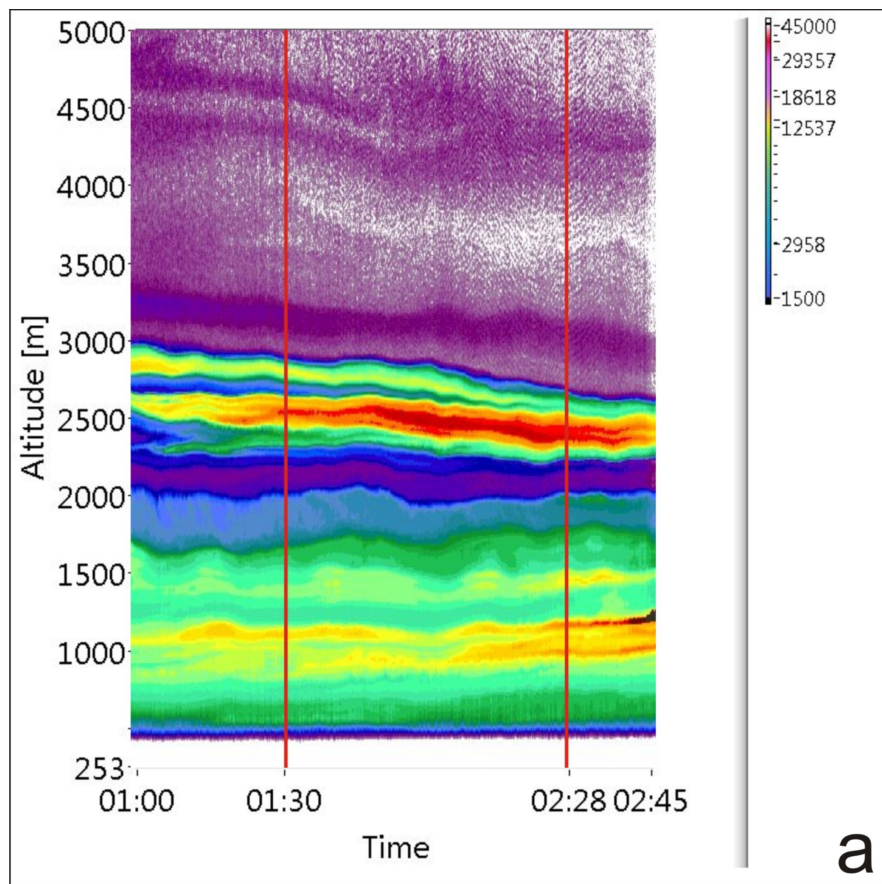

Volume Depolarization Ratio

- calibrated profile for 17.04 .2010
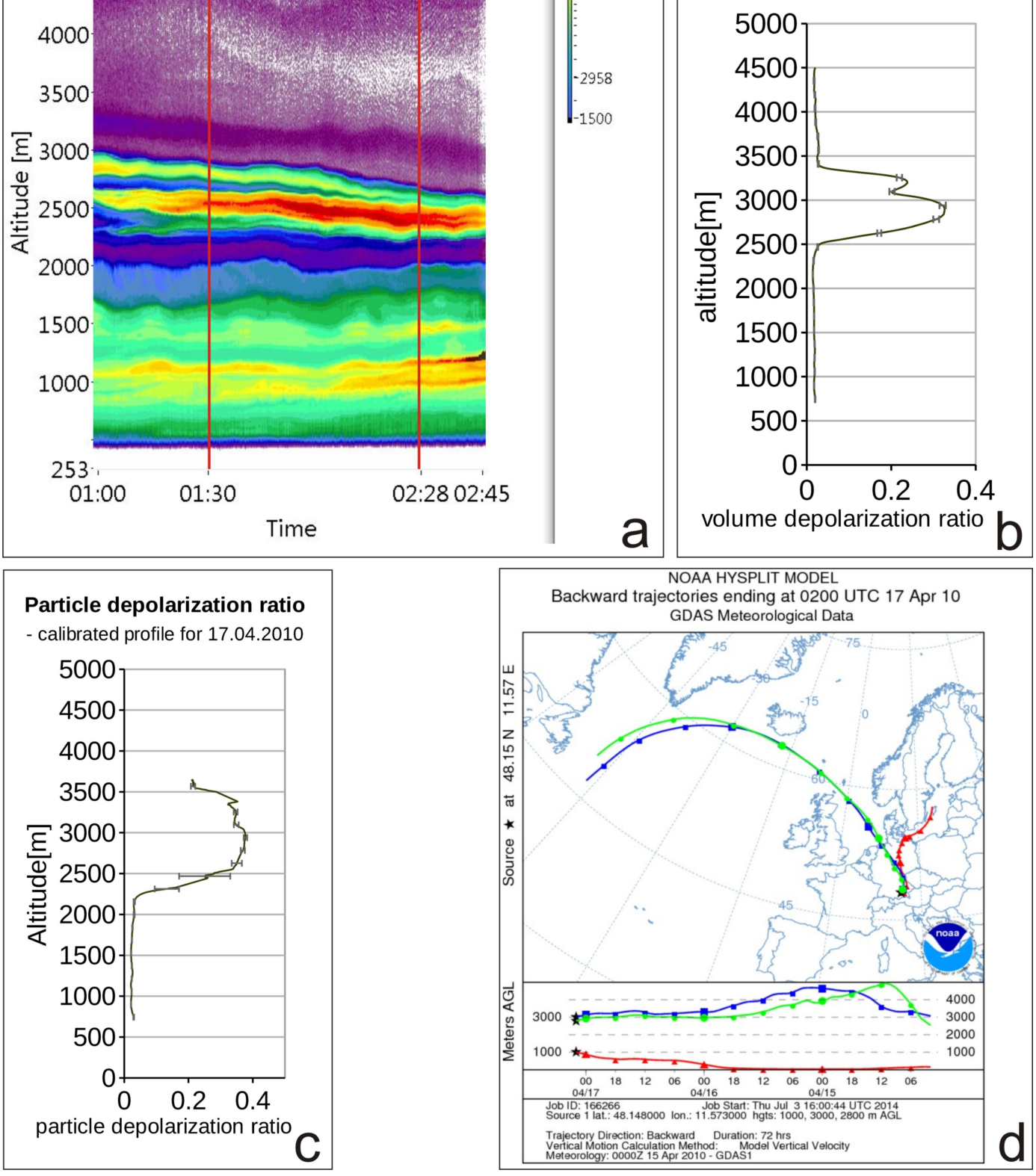

Figure 13. Data from $17^{\text {th }}$ of April 2010, at the Maisach-Munich lidar system a) range corrected time series at 532nm; b) volume linear depolarization ratio - corrected profile at 532nm - smoothed data, one hour average;; c) particle linear depolarization ratio - corrected profile at 532nm - smoothed data, one hour average; d) HYSPLIT back-trajectories analysis (-72h) for the detected layers, at the Munich site 
Atmos. Meas. Tech. Discuss., doi:10.5194/amt-2015-337, 2016

Manuscript under review for journal Atmos. Meas. Tech.

Published: 2 February 2016

(c) Author(s) 2016. CC-BY 3.0 License.
Atmospheric

Measurement

Techniques

Discussions

(c) (1)

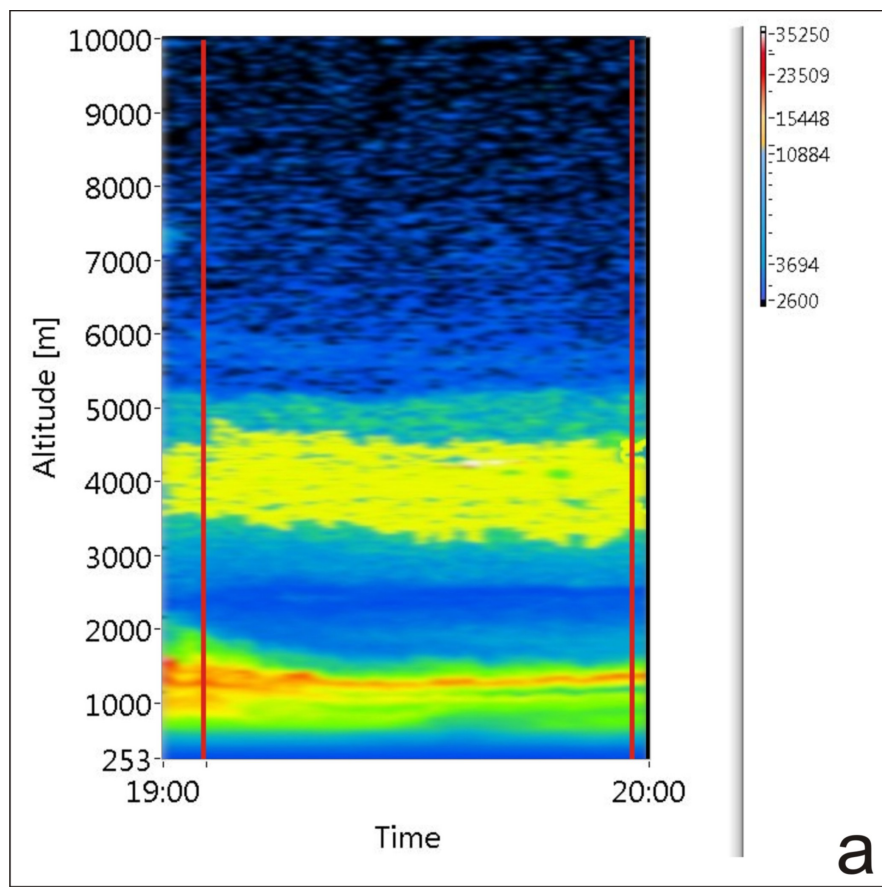

Volume depolarization ratio

- calibrated profile for 20.08.2012

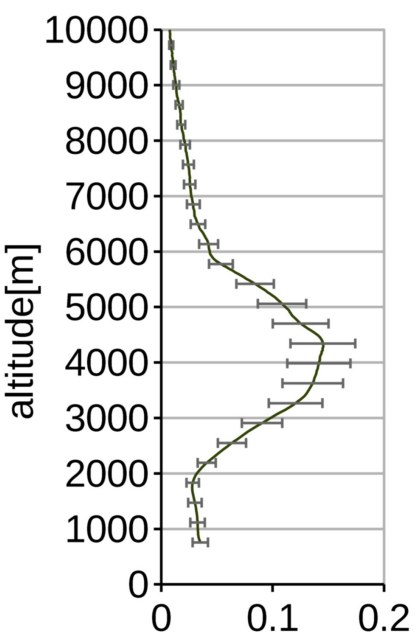

volume depolarization ratio
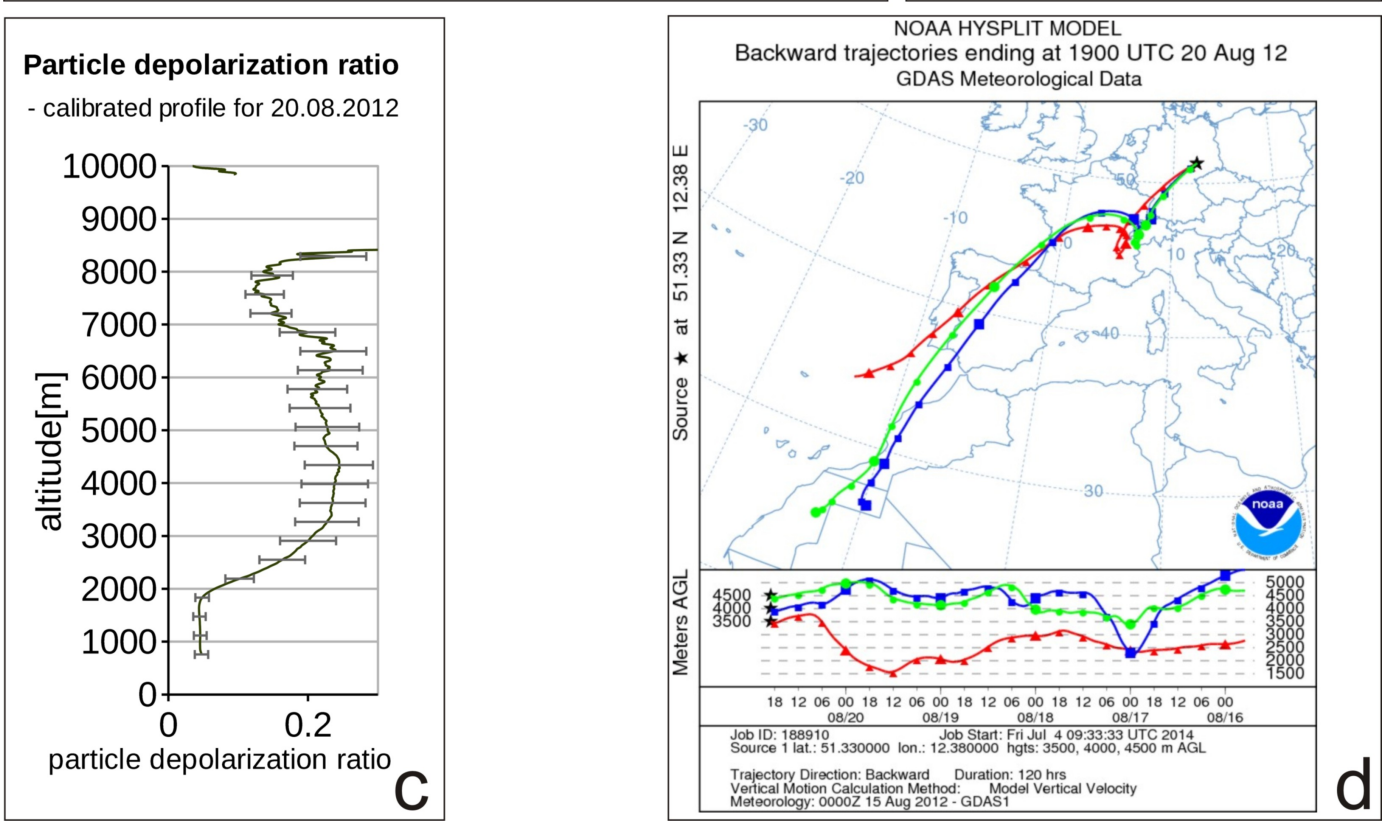

Figure 14. Data from $20^{\text {th }}$ of August 2012, at the PollyXT-Leipzig lidar system a) range corrected time series at 532nm; b) volume linear depolarization ratio - corrected profile at 532nm - smoothed data, one hour average; c) particle linear depolarization ratio - corrected profile at 532nm - smoothed data, one hour average; d) HYSPLIT back-trajectories analysis $(-120 \mathrm{~h})$ for the detected layers, at the Leipzig site 